\title{
High Throughput Screening to Identify Selective and Nonpeptidomimetic Proteasome Inhibitors As Antimalarials
}

\author{
Lydia Mata-Cantero,* Stanley C. Xie, Mercedes García, Joanne Coyle, Raquel Fernandez, \\ Alvaro Cortes Cabrera, David L. Gillett, Benigno Crespo, Francisco-Javier Gamo, Esther Fernández, \\ Leann Tilley, and Maria G. Gomez-Lorenzo
}

Cite This: ACS Infect. Dis. 2021, 7, 1818-1832

Read Online

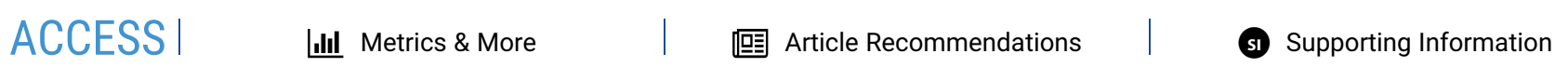

ABSTRACT: The Ubiquitin Proteasome System is the main proteolytic pathway in eukaryotic cells, playing a role in key cellular processes. The essentiality of the Plasmodium falciparum proteasome is well validated, underlying its potential as an antimalarial target, but selective compounds are required to avoid cytotoxic effects in humans. Almost 550000 compounds were tested for the inhibition of the chymotrypsin-like activity of the $P$. falciparum proteasome using a Proteasome-GLO luminescence assay. Hits were confirmed in an orthogonal enzyme assay using Rho110-labeled peptides, and selectivity was assessed against the human proteasome. Four nonpeptidomimetic chemical families with some selectivity for the $P$. falciparum proteasome were identified and characterized in assays of proteasome trypsin and

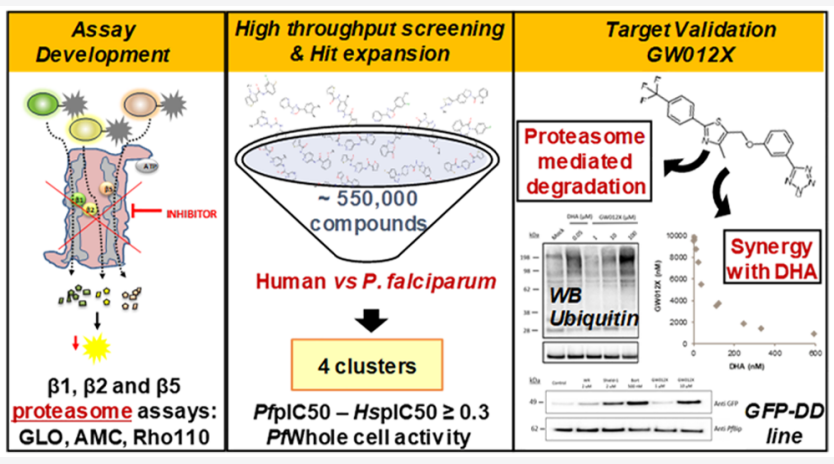
caspase activities and in parasite growth inhibition assays. Target engagement studies were performed, validating our approach. Hits identified are good starting points for the development of new antimalarial drugs and as tools to better understand proteasome function in P. falciparum.

KEYWORDS: Plasmodium falciparum, proteasome, nonpeptidomimetic inhibitors, high throughput screening, malaria drug discovery

\section{INTRODUCTION}

Human malaria, caused by the protozoan parasite Plasmodium falciparum, is one of the deadliest infectious diseases in the world, with more than 400000 deaths per year. ${ }^{1}$ Current firstline treatments in endemic countries are based on artemisinin combination therapies (ACTs). However, the parasite has developed resistance or tolerance to all antimalarials currently in use, including ACTs. Therefore, the identification of new therapies with novel modes of action, effective against different stages of the parasite, ${ }^{2}$ are urgently required.

A novel and well-validated target is the Ubiquitin Proteasome System (UPS). The UPS is the main proteolytic system in the cytoplasm of eukaryotic cells, regulating key processes such as cell cycle, protein trafficking, DNA repair, and signal transduction. The UPS core component is the proteasome, comprising a $26 \mathrm{~S}$ complex with a $20 \mathrm{~S}$ core, responsible for catalytic activity, and regulatory $19 \mathrm{~S}$ particles, located at one or both ends, that control entry of ubiquitylated proteins into the proteolytic sites. $20 S$ comprises four heptameric rings, with the outer rings formed by alpha subunits and the inner rings by beta subunits, including the catalytic caspase-like $(\beta 1)$, trypsin-like $(\beta 2)$, and chymotrypsin-like $(\beta 5)$ subunits. ${ }^{3}$ Due to its essential role, the UPS has been pursued as a therapeutic target in diseases such as cancer. Bortezomib was the first proteasome inhibitor approved by the US Food and Drug Administration in 2003 for multiple myeloma, and additional inhibitors have since been launched or tested in clinical trials, confirming its druggability and tractability as a therapeutic target. ${ }^{4}$

The UPS is a source of promising targets for drug development in malaria. ${ }^{5}$ Different proteasome inhibitors have been used to demonstrate the essentiality of the P. falciparum UPS at all stages of its development cycle: hepatic and blood (sexual and asexual) as well as mosquito stages. ${ }^{6-13}$ Moreover, proteasome inhibitors strongly synergise artemisinin-mediated killing of $P$. falciparum in vitro and $P$. berghei in vivo. ${ }^{7,8,14}$ Thus, new drugs targeting the proteasome have also the potential to overcome parasite resistance to artemisinin-related drugs. A major challenge for developing proteasome inhibitors as antimalarial agents is achieving good activity against the $P$.

Received: March 4, 2021

Published: May 28, 2021 


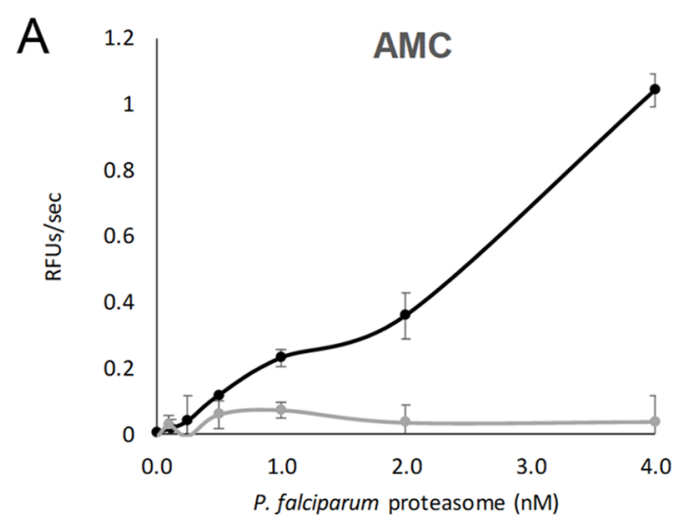

$\rightarrow$ Control $1 \rightarrow$ Control 2 (Bortezomib)

B

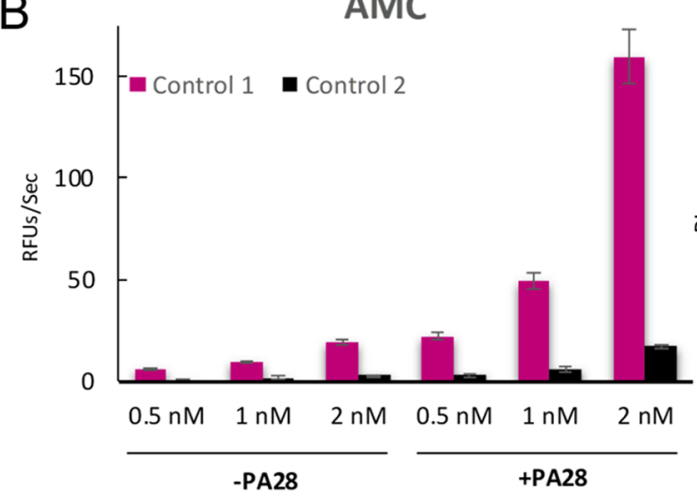

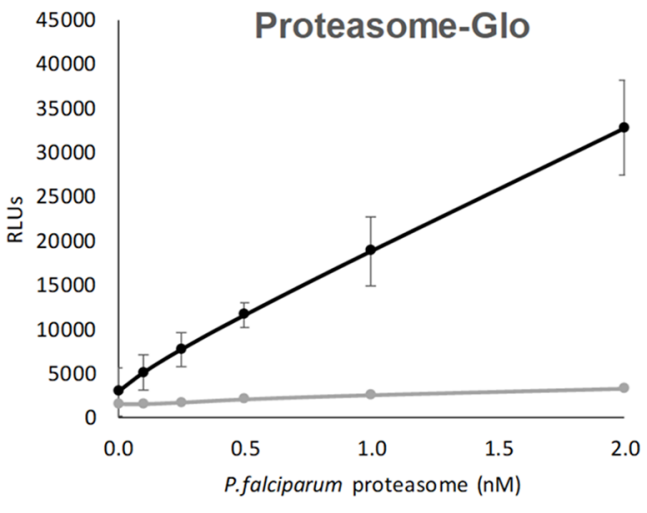

$\rightarrow$ Control $1 \rightarrow$ Control 2 (Bortezomib)

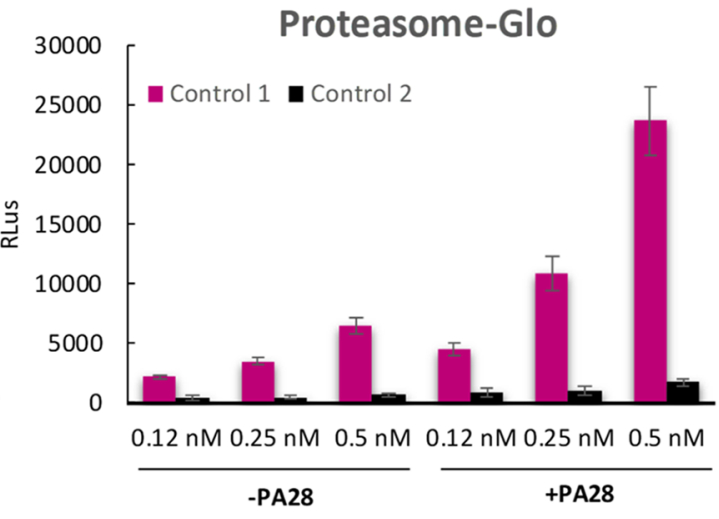

Proteasome-Glo

\begin{tabular}{|c|c|c|c|c|c|c|c|c|c|c|c|c|}
\hline \multirow[b]{3}{*}{ Pf proteasome } & \multicolumn{6}{|c|}{ AMC } & \multicolumn{6}{|c|}{ Proteasome-Glo } \\
\hline & \multicolumn{3}{|c|}{ No PA28 } & \multicolumn{3}{|c|}{ hPA28 } & \multicolumn{3}{|c|}{ No PA28 } & \multicolumn{3}{|c|}{ hPA28 } \\
\hline & $0.5 \mathrm{nM}$ & $1 \mathrm{nM}$ & $2 \mathrm{nM}$ & $0.5 \mathrm{nM}$ & $1 \mathrm{nM}$ & $2 \mathrm{nM}$ & $0.12 \mathrm{nM}$ & $0.25 \mathrm{nM}$ & $0.5 \mathrm{nM}$ & $0.12 \mathrm{nM}$ & $0.25 \mathrm{nM}$ & $0.5 \mathrm{nM}$ \\
\hline $\begin{array}{c}\text { Signal to } \\
\text { background }\end{array}$ & 6.3 & 5.6 & 6.7 & 7.9 & 8.1 & 9.4 & 5.0 & 7.2 & 9.3 & 5.3 & 10.2 & 13.5 \\
\hline $\mathbf{z}^{\prime}$ & 0.4 & 0.5 & 0.7 & 0.6 & 0.6 & 0.7 & 0.4 & 0.5 & 0.6 & 0.3 & 0.5 & 0.6 \\
\hline
\end{tabular}

C

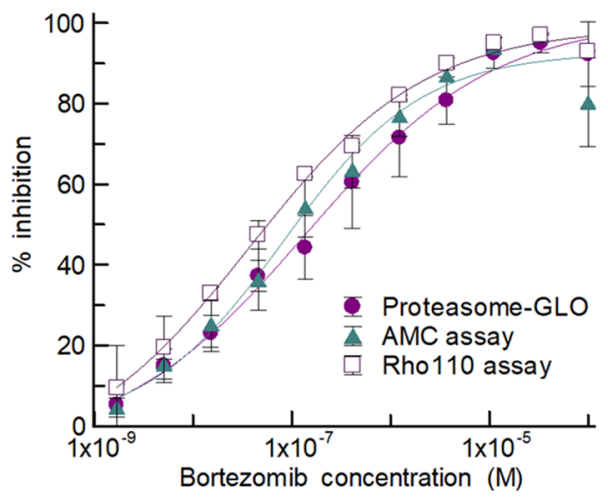

Figure 1. Chymotrypsin-like enzyme assay development. (A) P. falciparum proteasome titration in the AMC and Proteasome-GLO assays. Luminescence was measured at different proteasome concentrations in the absence (Control 1) or presence of the proteasome inhibitor, bortezomib (Control 2). Average and standard deviation of $n \geq 2$. (B) P. falciparum proteasome at the concentrationsindicated on the $\mathrm{X}$ axis were preincubated for $1 \mathrm{~h}$ with $50 \mathrm{nM}$ of the human activator hPA28 $\alpha$ in presence or absence of bortezomib (Control 2) $(100 \mu \mathrm{M})$. The same protocol was performed in parallel without hPA28 $\alpha$. Chymotrypsin-like proteasome activity was determined following addition of the substrate peptide Suc-LLVY labeled with AMC or AML (Proteasome-GLO), measuring fluorescence and luminescence, respectively. The ratio between the signal obtained in Control 1 (no inhibition) and Control 2 (inhibition) was calculated (signal to background) as well as the $\mathrm{Z}^{\prime}$ for each condition. Average and standard deviation values were determined using $n \geq 8$ replicates. (C) pIC50 determination ( proteasome chymotrypsin-like enzyme assays established. 100\% inhibition corresponds to the signal obtained with $100 \mu \mathrm{M}$ bortezomib and $0 \%$ the signal in the absence of inhibition. Average and standard deviation calculated for $n \geq 3$ replicates. 
falciparum proteasome, while minimizing activity against its human counterpart.

Selectivity depends on the harnessing of subtle differences between the human and P. falciparum active sites, as these exhibit a high degree of homology. The $\beta 5$ (chymotrypsin-like) active sites of $P$. falciparum and human proteasomes exhibit subtle differences, ${ }^{8,11,15,16}$ and the $P$. falciparum proteasome trypsin-like $(\beta 2)$ active site has an unusually open substratebinding pocket that can better accommodate bulky side chains. ${ }^{8}$ These divergences are being exploited to develop inhibitors with selectivity for the parasite proteasome. Structure-activity relationship analyses have revealed that potency against $P$. falciparum correlates with inhibition of the chymotrypsin-like $\beta 5$ activity, although coinhibition of trypsin-like $(\beta 2)$ activity enhances parasite killing. ${ }^{9,17,18}$ Similarly, inhibition of chymotrypsin-like $(\beta 5)$ activity correlates with cytotoxicity in mammalian cell lines. ${ }^{18}$ Partial inhibition of chymotrypsin-like activity in human cells is tolerated if the trypsin-like activity is not inhibited, providing therapeutic opportunities. ${ }^{19}$

To date, efforts to identify proteasome inhibitors as potential antimalarial compounds have largely concentrated on peptidemimetic inhibitors with reactive warheads that bind reversibly or irreversibly to the proteasome active sites. ${ }^{11}$ Unfortunately, these peptide-mimetics can have bioavailability or metabolic stability issues when administered orally. ${ }^{8,9,17}$

We previously identified cyanamides, which are nonpeptide inhibitors, with selectivity for the trypsin-like and caspase-like activities of the P. falciparum proteasome. ${ }^{13}$ They were inactive against the human proteasome, but they were also inactive against the chymotrypsin-like activity of the parasite proteasome and exhibited only a moderate parasite killing profile compared to compounds that inhibit the chymotrypsin-like activity.

In this work, the objective was to identify potent, selective, nonpeptide mimetic, small molecular weight inhibitors of the chymotrypsin-like parasite proteasome activity. Large scale in vitro culture of $P$. falciparum was undertaken to enable proteasome purification at scale, ${ }^{9}$ and differently formatted assays comparing $P$. falciparum and human proteasome were established. A high throughput screening (HTS) campaign with around 550000 compounds was run against the $P$. falciparum chymotrypsin-like proteasome activity, using the ProteasomeGLO luminescence assay as the primary readout. Hits were reanalysed in an orthogonal fluorogenic enzyme assay using the D-Pro-Rhodamine110 label (Rho110), and selectivity against the human proteasome was assessed. Analogues of the most promising compounds, with some selectivity for the parasite proteasome, were identified within the GlaxoSmithKline (GSK) collection. From this work, four new nonpeptide mimetic families were prioritized, and their activities were assessed in functional assays of the three proteasome activities, against the human immunoproteasome and in parasite growth inhibition assays. Assays linking proteasome inhibition with parasite killing were performed, thereby validating our approach. These new classes of proteasome inhibitors could be further progressed to develop antimalarial drugs with a novel mode of action to be used alone or in combination with artemisinin derivatives and/ or other antimalarials.

\section{RESULTS AND DISCUSSION}

Development of Enzyme Assays. In order to run an HTS campaign to identify new proteasome inhibitors selective for the P. falciparum proteasome, a set of enzyme assays was established. The primary screening campaign focused on the chymotrypsin- like activity of the $P$. falciparum proteasome, because the inhibition of this activity has been reported to be more lethal for the parasite than the targeting of other proteasome subunits. ${ }^{8,17}$ $P$. falciparum proteasome was obtained from infected red blood cells through a two-step column-based purification. ${ }^{8}$ Its chymotrypsin-like activity was initially assayed using the standard AMC assay. ${ }^{20}$ Cleavage of the fluorogenic substrate, Suc-Leu-Leu-Val-Tyr (Suc-LLVY), releases the 7-amino-4methylcoumarin (AMC) moiety. However, the large quantity of proteasome required to run a full HTS campaign using this assay represented a major bottleneck for the project.

To decrease the amount of proteasome required for the primary screening, the commercially available Proteasome-GLO luminescence assay was used. ${ }^{13,21}$ Proteasome-GLO assay makes use of the same well-established peptide substrate but relies on proteasome-mediated release of aminoluciferin (AML). The signal obtained in the absence of inhibition (control 1) was proportional to the amount of proteasome in the sample (Figure 1A). Inhibition of the chymotrypsin-like activity by bortezomib (control 2) led to the expected decrease in signal. AMC and Proteasome-GLO chymotrypsin-like assays were evaluated in the presence and absence of the human PA28 $\alpha$ activator (hPA28 $\alpha$ ) (Figure 1B), as it has been previously described that activation decreased the amount of proteasome needed in the assay. ${ }^{9,14}$ Proteasome concentrations tested were in the linear range of the assays. Proteasome-GLO provided higher sensitivity than the AMC assay allowing us to decrease the amount of proteasome 10 -fold, while maintaining the robustness of the assay $\left(\mathrm{Z}^{\prime}>0.4\right)$. The chymotrypsin-like activity of the $P$. falciparum proteasome increased 2 to 8 -fold upon addition of hPA $28 \alpha$, but the residual activity of the bortezomib-inhibited proteasome also increased, providing no advantage in terms of signal to background (S/B) and $\mathrm{Z}^{\prime}$ (Figure $1 B)$. Finally, the Proteasome-GLO assay in the absence of hPA2 $8 \alpha$ was further optimized in the 1536 well plate format and chosen for the primary HTS campaign as it allowed a 10 -fold increase in the number of compounds tested compared with the standard AMC assay. The main disadvantage of the luciferasebased assay is that it is prone to interference. ${ }^{22}$ Thus, an interference assay was established to identify compounds that interfere with the luciferase reporter or the luminescence readout (see M\&M for details).

Secondary assays to confirm, characterize, and assess the selectivity of the hits were required to progress the compounds. Orthogonal assays that use peptide substrates tagged with Rho110, instead of AML or AMC, were used. Suc-LLVYRho110, Ac-RLR-Rho110, and Ac-GPLD-Rho110 were employed for chymotrypsin-like, trypsin-like, and caspase-like proteasome activities, respectively, for $P$. falciparum and human (constitutive and immunoproteasome) proteasomes (SI Figure S1). The Rho110 assay requires the same amount of proteasome as the standard AMC assay. Its main advantage is a red-shifted readout $(530 \mathrm{~nm})$. The AMC label emits in the bluegreen spectral region $(460 \mathrm{~nm})$ and compound libraries tend to have greater interference in this region. ${ }^{23}$ The fluorescence signal was linearly proportional to the amount of proteasome and to the level of peptide substrate (SI Figure S1B).

The peptides were used at concentrations near the apparent $\mathrm{Km}$ determined in this experiment (SI Figure S1B). The bellshaped profile observed for peptides Suc-LLVY-Rho110 and AcRLR-Rho110 hampered the determination of an accurate $\mathrm{Km}$. This effect could be due to substrate inhibition or to the 
Proteasome-GLO primary assays

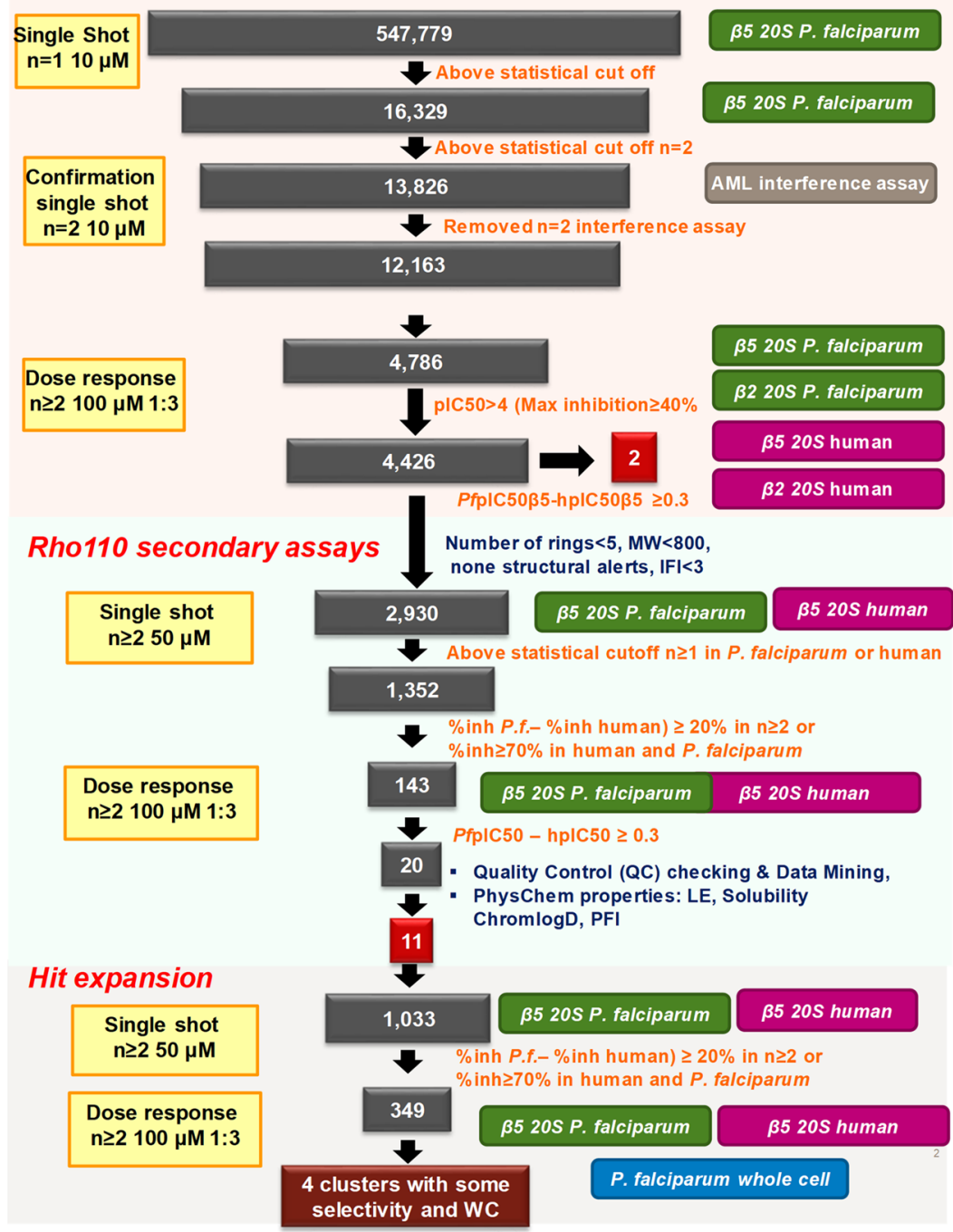

Figure 2. Progression cascade of the high throughput screening campaign. Hits identified in the P. falciparum chymotrypsin-like Proteasome-GLO primary campaign were filtered, and selected compounds were tested in the Rho 110 secondary assays. Hits confirmed in the Rho 110 secondary assays and with a difference in pIC50 with the human proteasome higher than 0.3 were selected for analogue searching (hit expansion). Four clusters showed some degree of selectivity for the P. falciparum proteasome and exhibited whole cell (WC) activity.

propensity of rhodamine to form dimers that can self-quench the fluorescence. $^{23}$

The pIC50 (calculated as pIC50 $=-\log (\operatorname{IC50}(\mathrm{M}))$ ); see Materials and Methods for data analysis) for the proteasome inhibitor bortezomib, which was used as a control in the screening campaign, was determined in the Rho110 $P$. falciparum chymotrypsin-like proteasome activity assay and compared with those of Proteasome-GLO and the reference assay AMC (Figure 1C). Its potency was in the same range in all assay formats.

High throughput primary screening campaign. Once the enzyme assays were in place, the primary screening campaign was run at a single shot (single concentration of $10 \mu \mathrm{M}$, one replicate) using the chymotrypsin-like Proteasome-GLO assay. A total of 547779 compounds (Figure 2) were tested. This includes a set of 14867 compounds that were shown to inhibit $P$. falciparum growth in previous whole cell phenotypic screening campaigns ("Whole Cell Set") such us the Tres Cantos Antimalarial Set (TCAMs). ${ }^{24}$ We also included 4612 analogues of known proteasome inhibitors described in the literature or found in our previous screening campaign ("Analogues Proteasome Inhibitors Set"). ${ }^{13}$ The remaining compounds were selected to cover the chemical diversity of the whole GSK collection of more than 2 million compounds ("Diversity Set").

The robustness of the assay was optimal with an average $\mathrm{Z}^{\prime}$ factor of 0.83 (Figure 3A). Compounds with a percentage of inhibition above the robust cutoff (average 17.5\%) were considered actives. The robust cutoff point was estimated using an algorithm ${ }^{25}$ that considers the mean value of Control 1 plus three times its standard deviation (SD). A total of 16329 compounds were selected for confirmation in duplicate at $10 \mu \mathrm{M}$ in the same assay format, representing a hit rate of $3 \%$ (Figure 2). The linear correlation between replicates was good (Figure 3B), with a $R^{2}$ of 0.9 . The percentage of confirmation was $84.7 \%$, with 13826 compounds being active in both replicates (Figure 2). Interference assays were performed to discard false positives (e.g., luciferase inhibitors). $12 \%$ of the hits were identified as interferences (Figure 3B yellow), leaving a total of 12163 active hit compounds (Figure 2). This represents a hit rate of $2.2 \% .257$ 

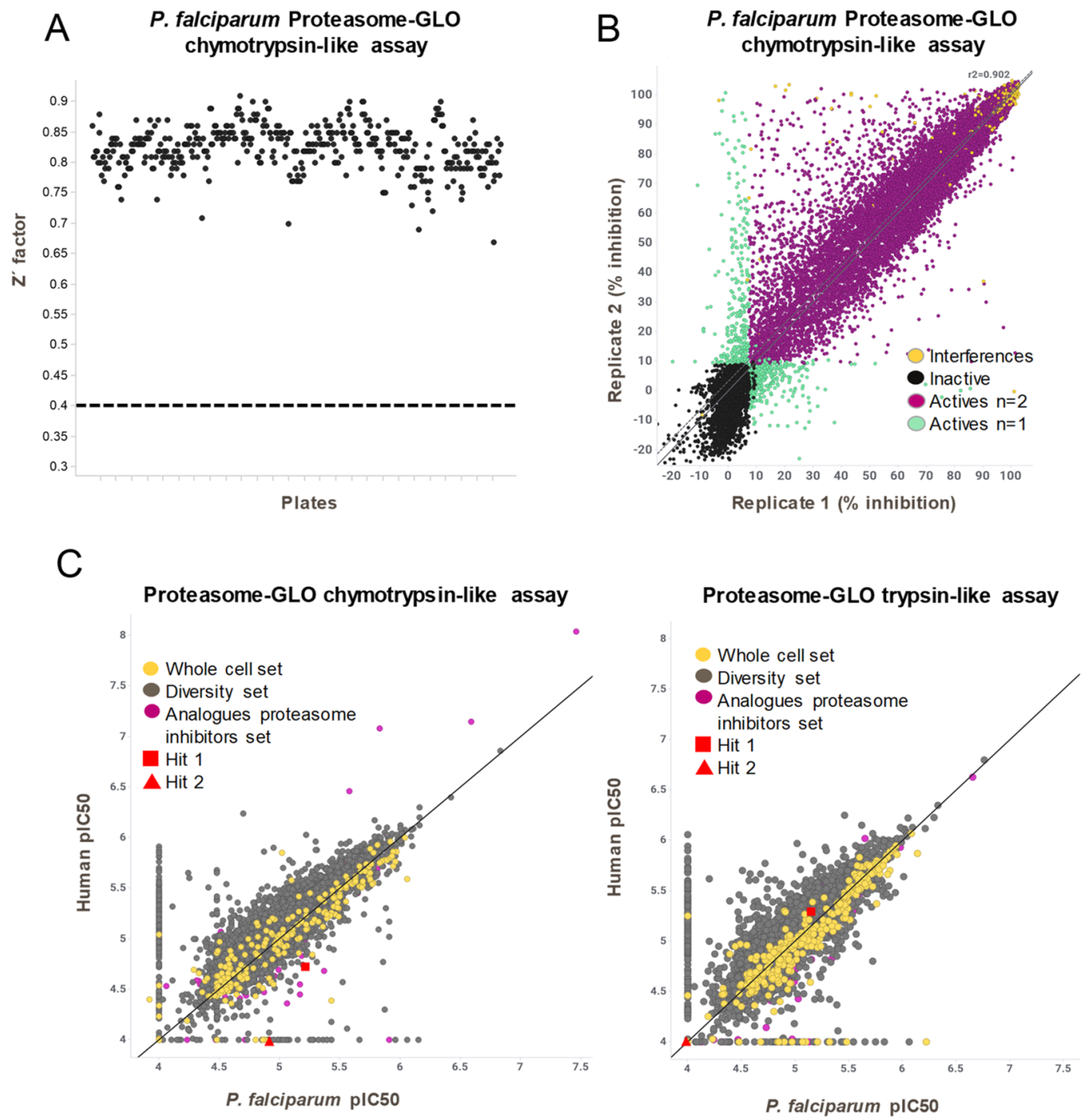

Figure 3. High throughput screening campaign using the Proteasome-GLO assay. (A) $Z^{\prime}$ factor calculated for every plate tested during the HTS campaign in the P. falciparum Proteasome-GLO assay (chymotrypsin-like). The dotted line represents the cutoff considered to validate a plate (0.4). (B) Compounds were confirmed in the P. falciparum chymotrypsin-like assay in duplicate at $10 \mu \mathrm{M}$ and correlation of the percentage of inhibition obtained for each replicate was calculated. Inactive compounds are colored black, active hits in at least one replicate are labeled in green and compounds active in both replicates are in pink. Compounds active in the interference assay (interferences) are highlighted in yellow. (C) Active hits were assayed at dose response starting at $100 \mu \mathrm{M}$ (1:3 dilutions). Graphs show the correlation of the pIC50 values obtained for the human and $P$. falciparum proteasomes in the chymotrypsin and trypsin-like assays. Inactive compounds are designated as pIC50 $=4$. The source of the compounds is labeled in different colors. The hits for which selectivity relative to the human proteasome was reconfirmed are highlighted in red. The lines in graphs B and $\mathrm{C}$ indicate a perfect correlation $(\mathrm{y}=\mathrm{x})$.

of the confirmed hits were analogues of known proteasome inhibitors, and 606 compounds came from the Whole Cell Set. In order to select the most drug-like compounds prior to dose response assays, a selection process was performed. Compounds were ranked by a score of desirability based on their physicochemical properties, Property Forecast Index (PFI), structural alerts, percentage inhibition, cytotoxicity, and promiscuity factor (IFI) (see M\&M for details). PFI is a widely used parameter at GSK, because it is a good predictor of developability of compounds, ${ }^{26}$ while IFI is calculated taking into account the number of assays run at GSK in which the compound has been active.

Thus, 4786 compounds were selected and further evaluated in Plasmodium and human chymotrypsin- and trypsin-like Proteasome-GLO assays in dose response assays starting at $100 \mu \mathrm{M}$ (Figures 2 and $3 \mathrm{C}$ ). The assay set is based on the information that coinhibition of the chymotrypsin-like and trypsin-like activities enhances parasite killing and that partial inhibition of the human chymotrypsin-like activity can be tolerated if the human trypsin-like activity is not inhibited. ${ }^{19} \mathrm{~A}$ total of 4426 compounds were confirmed with a pIC50 > 4 $($ IC50 $<100 \mu \mathrm{M})$ and a maximum asymptote above $40 \%$ inhibition at $100 \mu \mathrm{M}$.

The most potent compounds (in the nanomolar range) belonged to the Analogues of Proteasome Inhibitors Set, validating the approach taken for the screening. The pIC50s values obtained in $P$. falciparum and human assays were very similar for most of the compounds (Figure 3C). We detected some compounds that were more potent against $P$. falciparum chymotrypsin- and trypsin-like activities, but selectivity was not confirmed in further experiments. The only two compounds that kept some degree of selectivity ( 0.5 and 0.9 logs) for the $P$. 

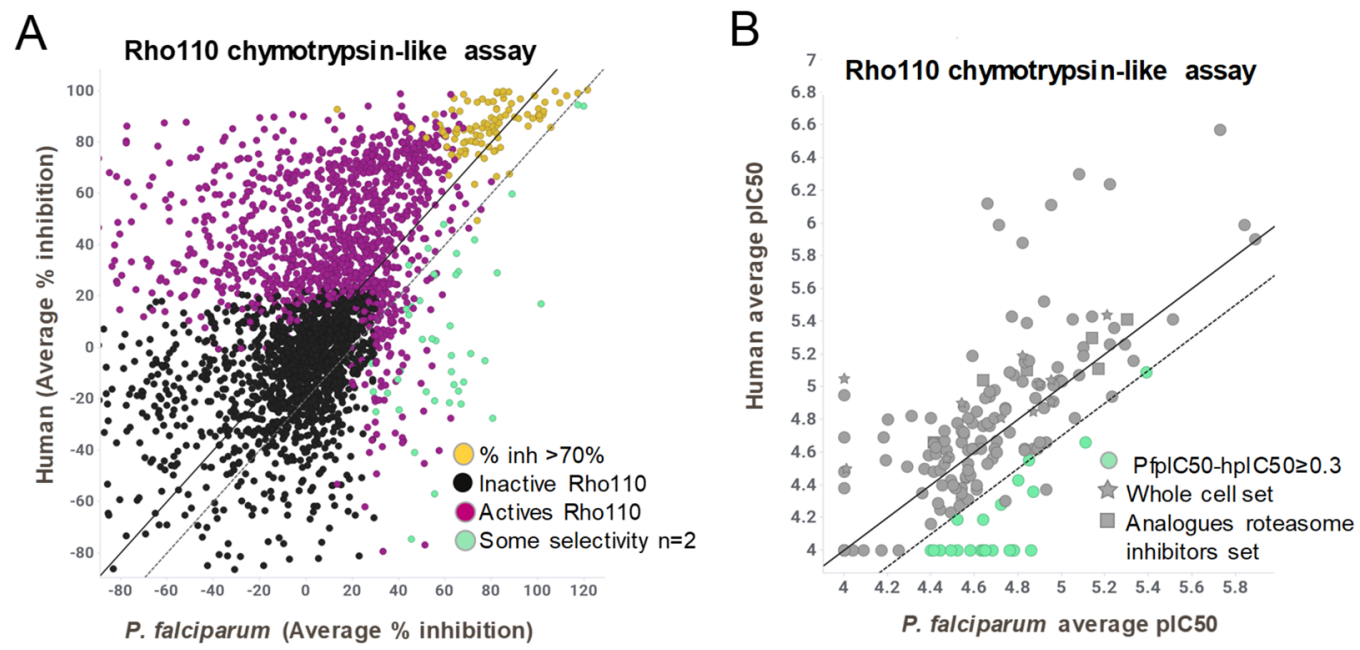

Figure 4. Hit characterization with the Rho110 secondary assay. (A) A selection of compounds was confirmed in the $P$. falciparum and human chymotrypsin-like Rho110 assays, performed in duplicate at $50 \mu \mathrm{M}$. The graph shows the correlation of the average of the percentage inhibition. Inactive compounds in all conditions are colored black, active compounds that were not progressed to dose response due to lack of selectivity are indicated in pink. Green and yellow represent compounds progressed to dose response experiments. In green are compounds inactive in both replicates in human or with a difference in the percentage inhibition $>20 \%$ in the two replicates tested (\% inhibition P. falciparum $-\%$ inhibition human). Compounds with a percentage inhibition $>70 \%$ in both species are colored in yellow. The black line indicates the perfect correlation $(y=x)$ while the dotted line represents $y=x+20$. (B) Compounds tested at dose response starting at $100 \mu \mathrm{M}$ using 1:3 dilutions. Correlation of the average pIC50 values recorded in the human and $P$. falciparum proteasomes (chymotrypsin-like activity). Inactive compounds $(\mathrm{pIC} 50<4)$ are designated as pIC50 $=$ 4. The sources of the compounds are indicated by different shapes. In green are compounds displaying differences in pIC50 values $\geq 0.3$. The black line indicates the perfect correlation $(y=x)$ while the dotted line represents $y=x+0.3$.

falciparum chymotrypsin-like proteasome activity in several validation rounds are highlighted in red in Figure 3 as Hit 1 and Hit 2. This low confirmation rate could be due to the low potency of the compounds (micromolar range) and because some of them did not reach $100 \%$ of inhibition. Unfortunately, none of the compounds that showed potency in the chymotrypsin-like activity assays were inactive against the human trypsin-like activity.

Hit Characterization Using the Rho110 Secondary Assay. Hits that were validated in the Proteasome-GLO dose response assays were tested in the Rho110 orthogonal assays. This assay also offered the opportunity to rescue compounds that were not identified as selective in the Proteasome-GLO assay because of interference with the luminescence readout.

The Rhol10 assay requires 10 -fold more proteasome; therefore, a harder filter was applied to select 2930 compounds that had drug-like properties (Figure 2). These compounds met the following criteria: aromatic rings $<5$, MW $<800$, no structural alerts, and IFI $<3$. Compounds were evaluated at single shot (single concentration of $50 \mu \mathrm{M}$ ) in the chymotrypsin-like Rho110 assay, in duplicate, for both $P$. falciparum and human constitutive proteasomes. SI Figure S2A shows that the percentage inhibition correlates well between replicates. The average of the robust cutoff was $31.2 \%$ and $24.9 \%$, and the average of $\mathrm{Z}^{\prime}$ factor was 0.57 and 0.75 , respectively, for the P. falciparum and human assays. A total of 1352 compounds exhibited a percentage inhibition above the robust cutoff in at least 1 of the replicates tested (46.1\% confirmation rate in Rho1 10 assay) (Figures 2 and 4A). This low confirmation rate could be explained by the low potency of the compounds or luciferase system interferences that were not detected in the interference assay. It is noted that the conditions for the luciferase-coupled reaction are not exactly the same in the interference and Proteasome-GLO assays. An excess of the AML substrate is used in the interference assay to give a measurable signal while a lower concentration of AML is generated by the proteasome in the Proteasome-GLO.

Compounds inactive in the human proteasome assay or that had a difference in the percentage inhibition higher than $20 \%$ between duplicates (Figure 4A green) were progressed to dose response assays in the chymotrypsin-like Rho110 assay. Moreover, compounds that displayed a percentage inhibition above $70 \%$ against both human and $P$. falciparum, which might prevent the detection of differences at $50 \mu \mathrm{M}$ (Figure $4 \mathrm{~A}$, yellow), were also progressed. In total, 143 compounds were progressed to dose response assays (Figure 2) and were tested at least twice. Figure 4B shows the correlation of pIC50 values obtained in human and P. falciparum proteasomes. PIC50 values are the average of $n \geq 2$ independent experiments. Only 20 compounds (Figure 2), all of them belonging to the Diversity Set, had a difference in pIC50 values higher than 0.3 (PfpIC50hpIC50 $\geq 0.3$ ), which corresponds to an IC50 ratio of 2 -fold. The potency of these compounds was low with pIC50 values between 4.4 and 5.4 (Figure 4B) (IC50 4-40 $\mu \mathrm{M}$ ). In order to look for analogues within the GSK collection with higher potency and selectivity, 11 hits (singletons), including Hit 1 and Hit 2, were prioritized based on their physicochemical properties (Figures 2, 3C, and 4B, SI table S1). Of these hits, 10 out of 11 had a carboxylic acid or its tetrazole bioisostere, and one compound possesses a sulphonamide group (SI table S1) which is present in proteasome inhibitors already published. ${ }^{13}$

Hit Expansion and Characterization of Selective Hits. A total of 1033 analogues of the 11 primary more selective hits were identified within the GSK compound collection (Figure 2 and SI table S1) and arranged in clusters. They were evaluated at single concentration in the chymotrypsin-like human and $P$. falciparum Rho110 proteasome assays in duplicate at $50 \mu \mathrm{M}$ to discard compounds exhibiting similar levels of inhibition of both proteasomes as well as inactive compounds. The criteria used to progress compounds to dose response assays were the same as 
A

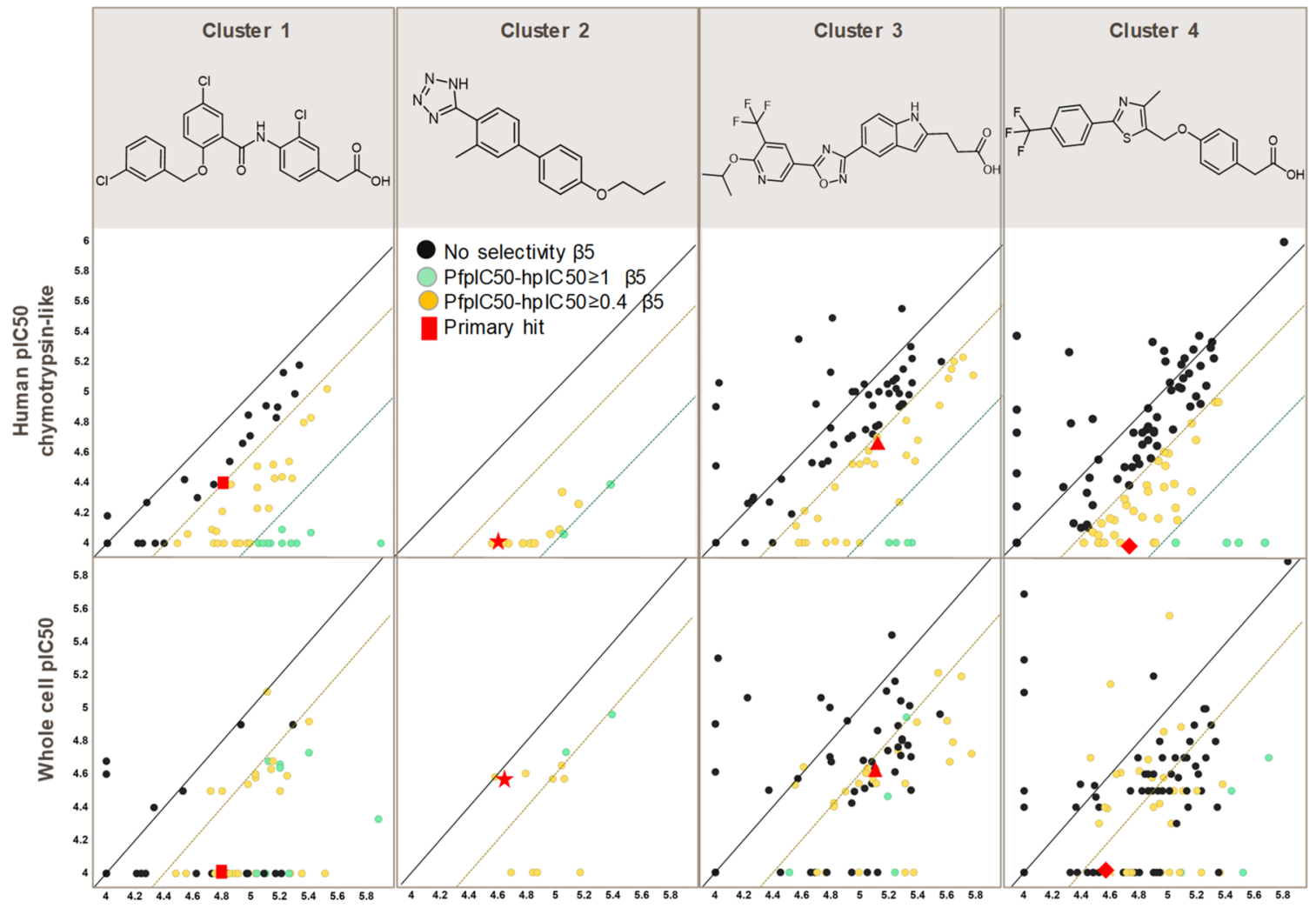

P. falciparum plC50 chymotrypsin-like

B
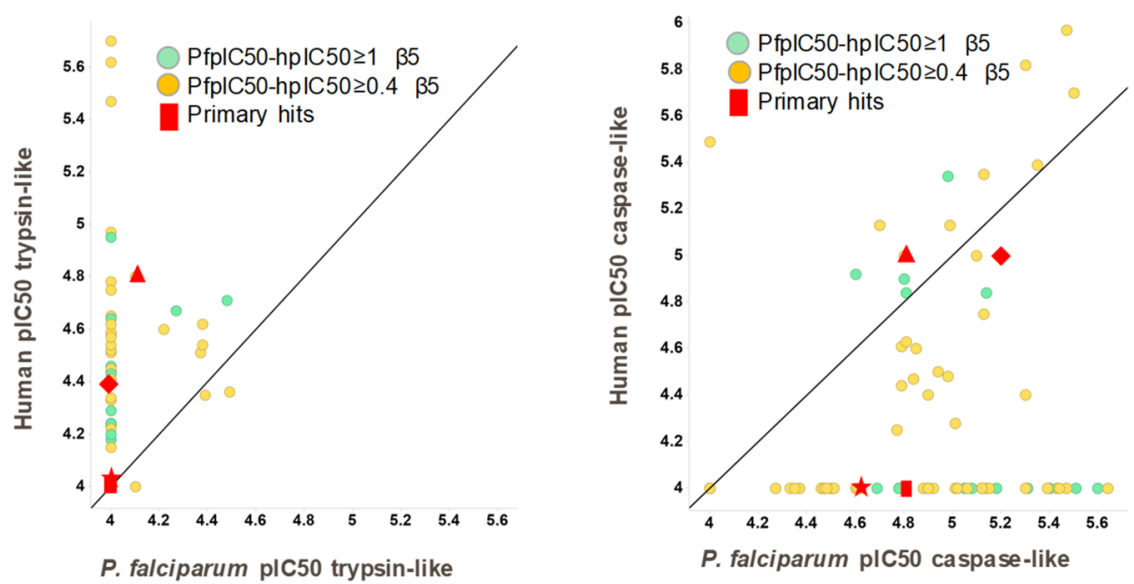

Figure 5. Hit expansion and characterization of the four prioritized clusters (Rho110 assays). (A) The four selected clusters are shown with a representative scaffold for each cluster. Compounds were subjected to dose response analysis starting at $100 \mu \mathrm{M}(1: 3$ dilutions) in the enzyme assays and at $50 \mu \mathrm{M}$ in the whole cell assay. Graphs in the top panel show the correlation between the average pIC50 values recorded against the human and $P$. falciparum chymotrypsin-like proteasome activities, while graphs in the bottom panel are the correlations between the average pIC50 values determined in the P. falciparum chymotrypsin-like assay and the pIC50 for inhibition of parasite in vitro growth ( $72 \mathrm{~h}$ ). Inactive compounds in the enzyme assays ( $\mathrm{pIC50}<4$ ) and in the whole cell assay ( $\mathrm{pIC50}<4.3$ ) are displayed as pIC50 $=4$. Compounds are labeled in different colors based on

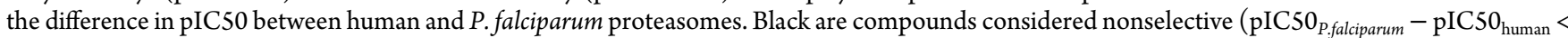
0.4). In yellow are compounds displaying a difference in the $\mathrm{pIC50}$ higher than 0.4 ( $\mathrm{pIC5} 0_{\text {Pfalciparum }}-\mathrm{pIC50} 0_{\text {human }} \geq 0.4$ ) and green are compounds with more than $1 \log$ difference in the pIC50 ( $\mathrm{pIC50}_{\mathrm{P} \text {.falciparum }}-\mathrm{pIC50}_{\text {human }} \geq 1$ ). Hits identified in the screening campaign are labeled in red. Different shapes correspond to different clusters. The black line is the perfect correlation $(y=x)$, the yellow dotted lines represent $y=x+0.4$ and the green dotted lines are $y=x+1$. (B) Correlation of the compounds chosen in the chymotrypsin-like assay (part A) in the trypsin- and caspase-like activities (human $v$ s $P$. falciparum proteasome). Colors and shapes are the same as in part A.

those in the previous step. In total, further 349 compounds were evaluated to assess their potency and selectivity in the chymotrypsin-like assays (Figure 2). In addition, potency in the parasite whole cell assay $(72 \mathrm{~h})$ was determined, measur- ing ${ }^{3} \mathrm{H}$-hypoxanthine incorporation during parasite replication. As a result of this profiling, 4 of the 11 initial clusters were prioritized, taking into consideration the selectivity, potency, and activity in the parasite whole cell assay. Figure 5A depicts the 
Table 1. Summary of data for the most interesting compounds identified (four clusters). The table compiles their PhysChem properties and pIC50 values $(\mathrm{pIC50}=-\log (\operatorname{IC50}(\mathrm{M})))$ in the enzymatic and cellular assays ${ }^{a}$

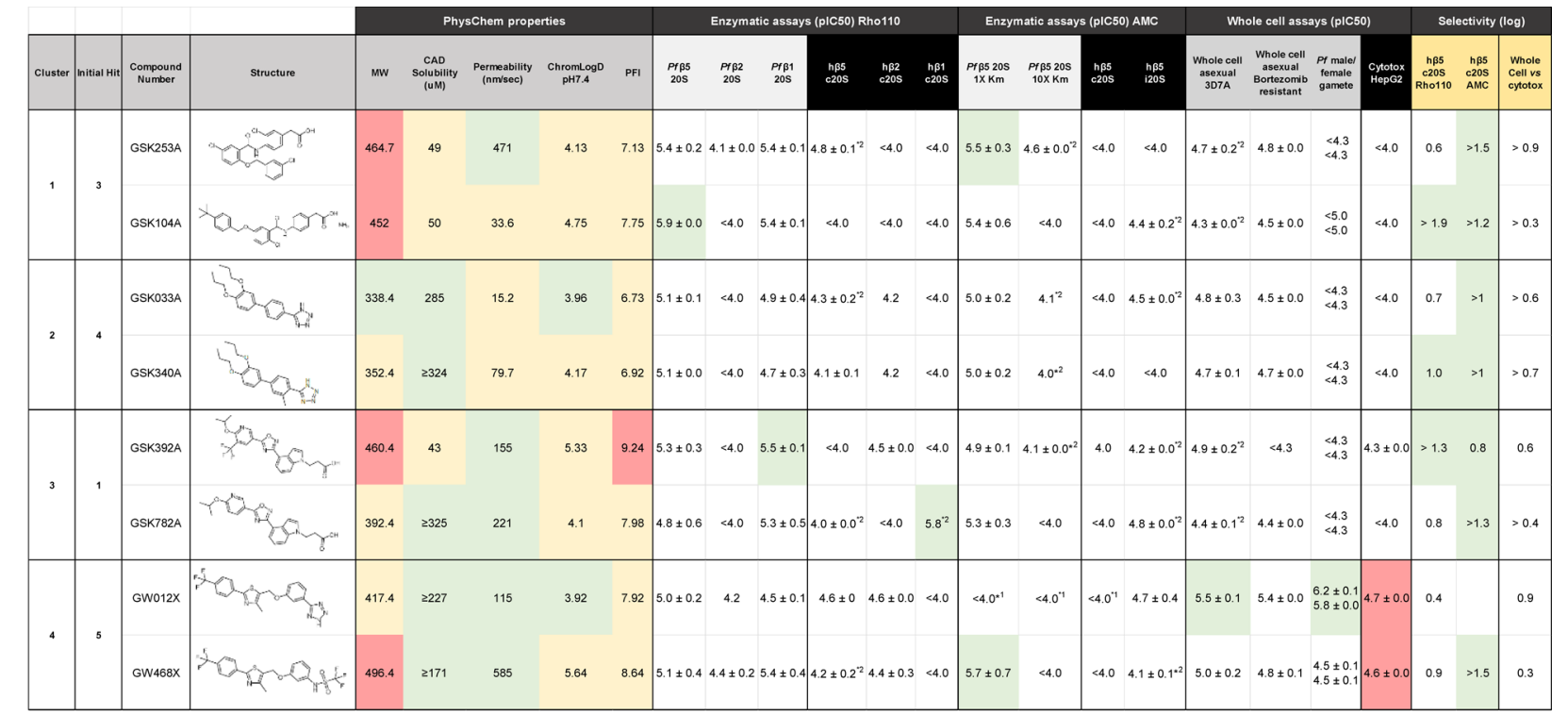

\begin{tabular}{|c|c|c|c|c|c|c|c|c|}
\hline & CAD solubility & ChromLogD & MW & Permeability & PFI & pIC50 Enzymatic and whole cell & Cytotox HepG22 & Selectivity (log) \\
\hline Green & $\geq 100$ & $\leq 4$ & $\leq 350$ & $\geq 100$ & $\leq 6$ & $\geq 5.5$ & & $\geq 1$ \\
\hline Yellow & $30-100$ & $5-6$ & $350-450$ & $10-100$ & $6-9$ & & & \\
\hline Red & $\leq 30$ & $\geq 6$ & $\geq 450$ & $\leq 10$ & $\geq 9$ & & $\geq 4.5$ & \\
\hline
\end{tabular}

$a_{*} 1$ : Interference could not be ruled out. $* 2$ : Only active copies were included in the average. The number of replicates differs between experiments, but at least two independent replicates were tested.

correlation between the pIC50 values obtained in the Rho110 enzyme assays (human and P. falciparum) and the P. falciparum whole cell assays. Original hits are also included and are highlighted in red. Cluster 3 was originally selected from the selective hit number 1 also identified in the Proteasome-GLO assay (Figure 3C). Analogues with higher potency in the enzyme and in the whole cell assay and higher selectivity than the original hits were identified (Figure 5A). Analogues were also tested against the caspase-like and trypsin-like proteasome activities (Figure 5B). Most of the analogues were inactive against the $P$. falciparum trypsin-like activity but active against the human one. The opposite situation was observed for the caspase-like activity. A clear structure-activity relationship (SAR) could not be established, probably due to the low potency of the compounds. However, a carboxylic acid or its tetrazole bioisostere seems to be important for activity in the majority of the compounds. These functional groups have not been previously described as features of proteasome inhibitors.

The most potent compounds for each cluster were retested and fully characterized. Results are compiled in Table 1. Inhibition of the P. falciparum and human chymotrypsin-like proteasome activities was confirmed in the AMC fluorescence assay, which is considered the gold standard assay to measure proteasome activities. The resulting $\mathrm{pIC50}$ values were similar to the ones obtained in the Rhol10 assay for the majority of the compounds. Some small differences were found for compounds belonging to cluster 3 and for compound GW012X, which seems to have some kind of interference in the AMC assay. The selectivity index in the AMC assay was a little bit higher than with Rho110, being in the order of $1 \log$ for the four clusters. Compounds were also assayed in the AMC assay in the presence of higher peptide concentrations, i.e., at 10-fold its $\mathrm{Km}$ (Table 1). Competition with the peptide substrate was observed, as the activities of the compounds were abolished or significantly decreased. In addition, compounds were evaluated in the human immunoproteasome AMC assay showing a higher potency against this isoform, but the selectivity was maintained (Table 1).

Curves are presented in the SI Figure S3. Some compounds did not reach $100 \%$ inhibition. This behavior has been observed previously with other inhibitors ${ }^{9,14}$ and may be explained by a nonspecific degradation of the substrate (due to other proteasome activities not inhibited by the compound or present as impurities in the proteasome sample). The failure to reach $100 \%$ inhibition is most evident in the AMC assay, but it did not affect the pIC50 determination, which is taken as half of the maximum inhibition. For the human proteasome, an increase in the signal (decrease in the percentage inhibition) was observed in a dose-dependent manner in both assays, although it is most prominent in the AMC-based assay. The most obvious explanation would be compound interference, but this seems unlikely given that it is apparent only with human proteasome and is evident at two different wavelengths. Another possible explanation is an increase in human proteasome activity at certain concentrations.

The potency (pIC50) of the compounds in the whole cell assays is lower than that obtained in the enzymatic assays (Table 1). This decrease in potency could be due to permeability issues but also to the cellular context. For example, the level of natural substrates in the cell could affect the potency of the compounds. Compounds were evaluated in parallel in P. falciparum 3D7A and a bortezomib-resistant isogenic strain of 3D7A-B 1a, ${ }^{9}$ which has two mutations in the $\beta 5$ subunit (Met105Ile and Leu113Phe). The pIC50 values were similar (Table 1 and SI Figure S4). We conclude that the bortezomib resistant strain did not show cross-resistance to the compounds tested, as none 

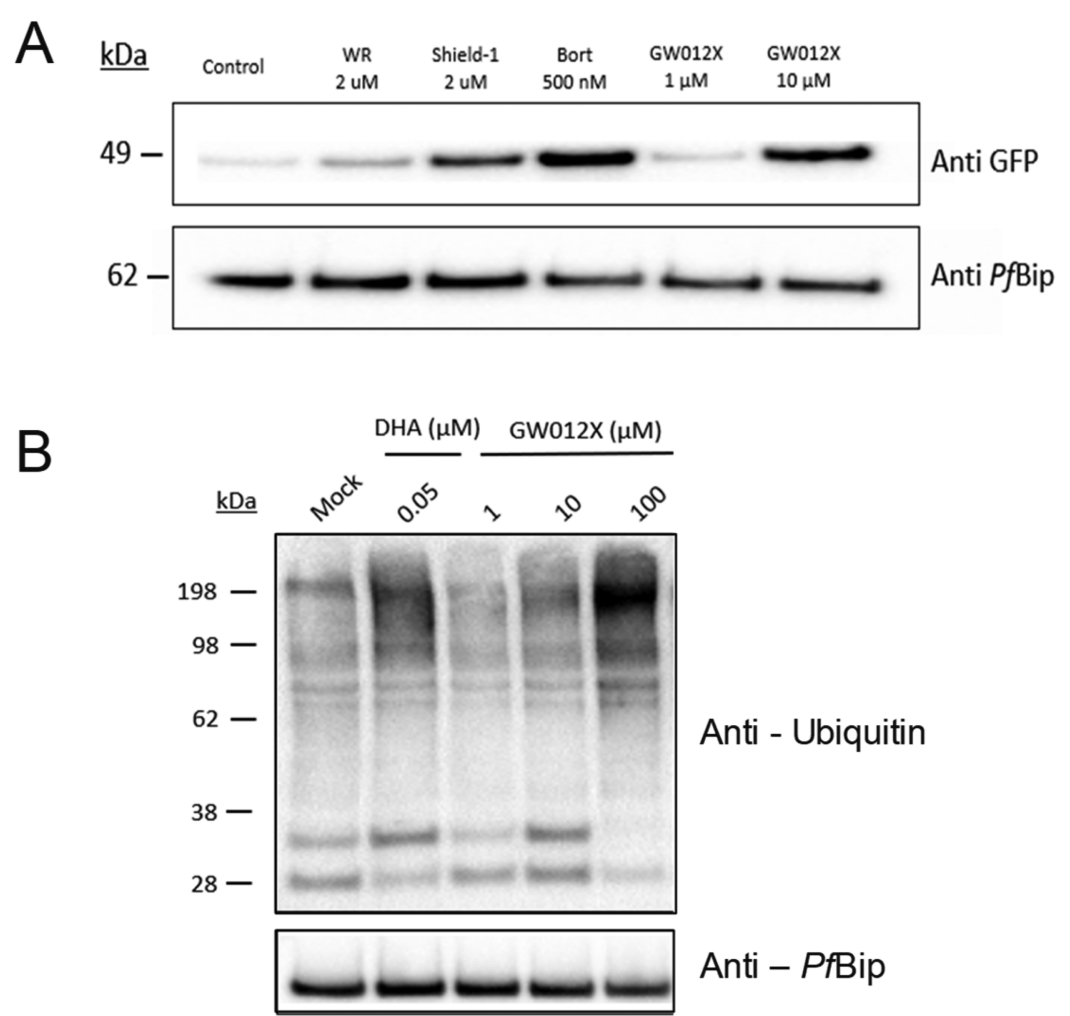

Figure 6. GW012X inhibits proteasome-mediated degradation of a destabilized protein in P. falciparum. (A) Trophozoites (GFP-DD transfectant line) were treated with no drug (control), WR99210 (WR), Shield-1, bortezomib (Bort), or GW012X at the indicated concentrations for 3 h. Cell extracts were subjected to Western blotting and probed for GFP and the loading control, PfBip. (B) 3D7 trophozoites were treated with DHA or GW012X for $1.5 \mathrm{~h}$. Mock samples represent parasites treated with DMSO $(0.02 \%)$. Parasite cell lysates were probed for ubiquitylated proteins and the loading control, $\mathrm{P} f$ Bip. Two independent repeats are presented in Figure S5.

exhibited a resistant/wild type IC50 ratio higher than 3 (e.g., difference in pIC50 of 0.5 ), which is our standard cutoff. These data indicate that the mode of binding of the compounds to the proteasome is different than those of bortezomib and other peptide-based inhibitors. In addition, compounds were tested for activity against sexual stages of the parasite by dual gamete formation assay $^{27}$ (Table 1). Compounds belonging to cluster 4 were active against this parasite stage, as expected for a proteasome inhibitor. We did not observe activity with the other compounds, but this could be related with the low potency shown in the whole cell assay. In our experience, the potency obtained in the dual gamete assay is around 10-fold lower than that in the asexual assay. The cytotoxicity of the compounds was evaluated against HepG2 cells. Most of the compounds were considered inactive in this assay, as their IC50 values were higher than $100 \mu \mathrm{M}(\mathrm{pIC} 50<4$, that is, IC50 $>100 \mu \mathrm{M})$, but we could not determine a selectivity index above 1 log in whole cells due to the low potency of the compounds against the parasite. In the case of cluster 4 , compounds had a pIC50 in the cytotoxicity assay of 4.7 (GW012X) and 4.6 (GW468X) (which means IC50s of 19.9 and $25.1 \mu \mathrm{M}$, respectively), with the selectivity index being 0.9 logs in the case of compound GW012X. The activity in the HepG2 assay could be due to the partial inhibition of the human proteasome but also to the interaction with other unknown human targets.

Representative compounds for the four clusters identified could be considered as interesting starting points for drug development. Compounds belonging to cluster 2 (GSK033A and GSK340A) exhibit good solubility and moderate lipophilicity, although their permeability has room for improve- ment (Table 1). Compound GW012X from cluster 4 presents the most balanced profile (Table 1). It is also the compound with the best $P$. falciparum whole cell activity $($ IC50 $=3.1 \mu \mathrm{M})$ and represents a good candidate for further in vivo profiling.

Validation of Compound GW012X as a Proteasome Inhibitor. GW012X was chosen for target engagement studies, as it exhibits the highest activity in the P. falciparum whole cell assay, with an IC50 in the low micromolar range. In order to demonstrate that GW012X inhibits parasite growth by specifically inhibiting the proteasome activity in P. falciparum, a transfectant line episomally expressing GFP fused to a destabilization domain (DD) was used. Under normal culture conditions, DD is recognized by the parasite's ubiquitinproteasome system, leading to proteasome-dependent degradation of GFP. ${ }^{28}$ Addition of a small molecule ligand, Shield-1, stabilizes the GFP-DD and prevents degradation (Figure 6A). Similarly, the GFP-DD band was evident when the proteasome was inhibited by bortezomib (Figure 6A). By contrast, no GFPDD band was observed when parasites were treated with WR99210, an antifolate with a distinct mechanism of action. Treatment of parasites with $10 \mu \mathrm{M}$ GW012X resulted in the accumulation of the GFP-DD (Figure 6A, S5A). These data support the hypothesis that GW012X exerts its parasite killing activity by inhibiting the proteasome activity of $P$. falciparum.

We also examined the effect of GW012X on the global level of protein ubiquitylation. Treatment with proteasome inhibitors has been previously reported to lead to a build-up of intracellular poly ubiquitin. ${ }^{13,29}$ Similarly, DHA, which damages proteins and compromises proteasome activity, ${ }^{28}$ leads to a build-up of poly ubiquitin (Figure 6B, S5B). Here, we show that treatment of $P$. 
falciparum with $100 \mu \mathrm{M}$ GW012X results in a similar increase in the level of polyubiquitylated protein (Figure 6B, S5B), a further indication that GW012X exerts its antimalarial activity by inhibiting proteasome activity.

Stage-dependent parasite killing was evaluated using flow cytometry of parasites labeled with a nucleic acid-binding dye. $P$. falciparum cultures are killed by exposure to a short $(3 \mathrm{~h})$ pulse of GW012X at ring or trophozoite stages, showing that the compound is fast acting and active at different erythrocytic stages. The $\mathrm{IC} \mathrm{O}_{3 \mathrm{~h}}$ values for rings $(7.9 \mu \mathrm{M})$ and trophozoites $(4.2 \mu \mathrm{M})$ were only a few-fold higher than those for the $72 \mathrm{~h}$ exposure $(1.5 \mu \mathrm{M})$ and in the range of the IC50 values observed in the DD-GFP line (Figure 6 and Table 2). This IC $50_{72 \mathrm{~h}}$ value obtained by flow cytometry was also similar to that obtained by ${ }^{3} \mathrm{H}$-hypoxanthine incorporation $3.1 \mu \mathrm{M}$ ( $\mathrm{pIC50}=5.5$ in Table 1).

Table 2. Early Ring Stage Cam3.II Strain Parasites (0-7 h.p.i.) Were Exposed to GW012X for $3 \mathrm{~h}$, and 3D7 Strain Parasites Were Exposed to GW012X for $72 \mathrm{~h}$ (Initiated at Ring Stage) or $3 \mathrm{~h}$ (at Mid-Trophozoite Stage) ${ }^{a}$

$\begin{array}{cccc} & 3 \mathrm{~h} \text { rings (Cam3.II) } & 3 \mathrm{~h} \text { trophozoites (3D7) } & 72 \mathrm{~h}(3 \mathrm{D} 7) \\ \text { IC50 }(\mu \mathrm{M}) & 7.9 \pm 1.2 \mu \mathrm{M} & 4.2 \pm 1.9 \mu \mathrm{M} & 1.5 \pm 0.5 \mu \mathrm{M}\end{array}$

${ }^{a}$ Viability was determined in the next cycle. For the $3 \mathrm{~h}$ ring stage assay, the data represent the average $\pm \mathrm{SD}$ from three independent experiments. For the $3 \mathrm{~h}$ trophozoite and $72 \mathrm{~h}$ assay, data are the average \pm half range from two independent experiments, each in technical duplicate.

The fast rate of killing of the compound was confirmed by the measuring of new invasions of prestained erythrocytes by flow cytometry, ${ }^{30}$ following exposure for 24 and $48 \mathrm{~h}$. Bortezomib (fast), chloroquine (fast), pyrimethamine (moderate), atovaquone (slow), and artesunate (fast) were used for comparison. Compound GW012X exhibited a fast killing profile similar to artesunate, chloroquine, and bortezomib (Figure 7A). This fast killing profile is consistent with that of GW012X acting through proteasome inhibition to kill P. falciparum.

Proteasome inhibitors have been shown to synergise the activity of artemisinin against $P$. falciparum. ${ }^{7,9}$ Here, we treated an artemisinin resistant (Kelch13 mutant R539T) line with combinations of GW012X and DHA at different concentrations. A $3 \mathrm{~h}$ treatment of GW012X at $3.75 \mu \mathrm{M}$ exerted only a minor inhibitory effect on parasite viability. By contrast, when the same dose of GW012X was used in combination with DHA, it substantively enhanced the activity of DHA (Figure 7B, left panel; S6). Isobologram curves illustrate the effectiveness of different combinations of two inhibitors. ${ }^{31}$ The synergy between GW012X and DHA is evidenced by the concave nature of the isobologram curve (Figure 7B, right panel). Hence, as is the case for other known classes of proteasome inhibitors, GW012X is active at the early ring stage of artemisinin resistant parasites and shows synergistic activity with artemisinin against a Kelch13 mutant of $P$. falciparum.

\section{MATERIALS AND METHODS}

Proteasome Purification. Erythrocytes infected with synchronized late stage 3D7 parasites ( $\sim 10 \%$ parasitaemia) were harvested by saponin lysis $(0.05 \% \mathrm{w} / \mathrm{v}$ in PBS $)$ and washed twice in diluted saponin $(0.0025 \% \mathrm{w} / \mathrm{v}$ in PBS) with an additional wash in PBS until the supernatant became clear. Harvested pellets were stored at $-80{ }^{\circ} \mathrm{C}$ until needed. $P$. falciparum $20 \mathrm{~S}$ proteasome was enriched from infected erythrocytes (6-10 L of initial complete culture) using a twostep chromatographic procedure as previously described. ${ }^{9}$

Preparation of Assay Plates with Compounds. Compounds were dissolved in $100 \%$ DMSO (stock solution of $1 \mathrm{mM}$ or $10 \mathrm{mM}$ ). The final DMSO concentrations in the assays were $1 \%$ for enzyme assays and $0.5 \%$ for whole cell assays. An echo dispenser was used to add compounds. Wells with only DMSO were included as Control 1, and proteasome inhibitors were included at $100 \mu \mathrm{M}$ as Control 2. Bortezomib was used for chymotrypsin- and caspase-like activities and MG132 for trypsin-like activity. Proteasome inhibitors were also included in dose response assays to assess the assay quality.

Proteasome-GLO Activity Assay. Chymotrypsin-like or trypsin-like activities were assayed following the manufacturer's instructions. Human 20S proteasome from erythrocytes (Boston Biochem) or P. falciparum proteasome isolated from the parasite (see above) were adjusted in HEPES buffer $(10 \mathrm{mM}$ HEPES, $1 \mathrm{mM}$ DTT, $2 \mathrm{mM}$ ATP, $0.1 \mathrm{mg} / \mathrm{mL}$ BSA) at different concentrations depending on the proteasome activity and proteasome batch: $0.15-0.3 \mathrm{nM}$ ( $P$. falciparum chymotrypsinlike; AML), 0.05-0.1 nM (human chymotrypsin-like; AML), 0.6-1 nM (P. falciparum trypsin-like; AML), 0.2-0.3 nM (human trypsin-like: $\mathrm{AML})$. Three $\mu \mathrm{L}$ of each proteasome solution was added to the 1536-well white plates (Greiner) with compounds and incubated for $1 \mathrm{~h}$. Then, $3 \mu \mathrm{L}$ of the Proteasome-GLO reagent and the corresponding peptide (40 $\mu \mathrm{M}$ Suc-LLVY-AML for chymotrypsin and $30 \mu \mathrm{M}$ Z-LRR-AML for trypsin activities) were added, and the mixture was incubated from $10 \mathrm{~min}$ up to $1 \mathrm{~h}$. Luminescence was read in Viewlux or Envision plate readers (PerkinElmer). The protocol was the same for $\mathrm{Z}^{\prime}$ experiments with the activator hPA28 $\alpha$, but hPA28 $\alpha$ (final concentration of $50 \mathrm{nM}$ ) and proteasome were preincubated for $1 \mathrm{~h}$ before being added to the plates. Activator was expressed and purified following the method previously described. ${ }^{32}$

Interference Assay. D-Aminoluciferin (AML) from Stratech was prepared in the HEPES buffer described above, and $3 \mu \mathrm{L}$ was added to white 1536-well plates with compounds to a final concentration of $20 \mathrm{nM}$. HEPES buffer (free of AML) was added to control 2 wells to normalize data (100\% inhibition). Plates were incubated for $1 \mathrm{~h}$ at room temperature. Then, $3 \mu \mathrm{L}$ of the luciferase detection reagent (Promega) was added. After 30 min, luminescence was measured in a Viewlux plate reader.

Fluorescence Proteasome Activity Assays (AMC and Rho110). Proteasome activities were assayed with fluorogenic peptide substrates labeled with 7-amino-4-methylcoumarin (AMC) from Sigma-Aldrich or D-Pro-rhodamine 110 (Rho110), synthesized by Cambridge Research Biochemicals. Human $20 \mathrm{~S}$ proteasome, human immunoproteasome (Boston Biochem), or P. falciparum proteasome were dissolved in assay buffer ( $50 \mathrm{mM}$ Tris buffer $\mathrm{pH} 7.5,5 \mathrm{mM} \mathrm{MgCl}, 1 \mathrm{mM}$ EDTA, $50 \mathrm{mM} \mathrm{NaCl}, 1 \mathrm{mM}$ DTT, $2 \mathrm{mM}$ ATP, $0.1 \mathrm{mg} / \mathrm{mL}$ BSA) at different concentrations depending on their batch and activities: $P$. falciparum chymotrypsin-like (AMC) at $2 \mathrm{nM}$, human chymotrypsin-like (AMC) at $0.25-1 \mathrm{nM}$, immunoproteasome chymotrypsin-like (AMC) at $0.15 \mathrm{nM}, P$. falciparum chymotrypsin-like (Rho110) at 1-2 nM, human chymotrypsin-like (Rho110) at $0.25-1 \mathrm{nM}, P$. falciparum trypsin-like (Rho110) at 2-6 nM, human trypsin-like (Rho110) at $1-3 \mathrm{nM}, P$. falciparum caspase-like (Rhol10) at 5-10 $\mathrm{nM}$, and human caspase-like (Rho110) at $1-3 \mathrm{nM}$. Four $\mu \mathrm{L}$ of each proteasome solution was added to the corresponding low volume black 384-well plates 
A

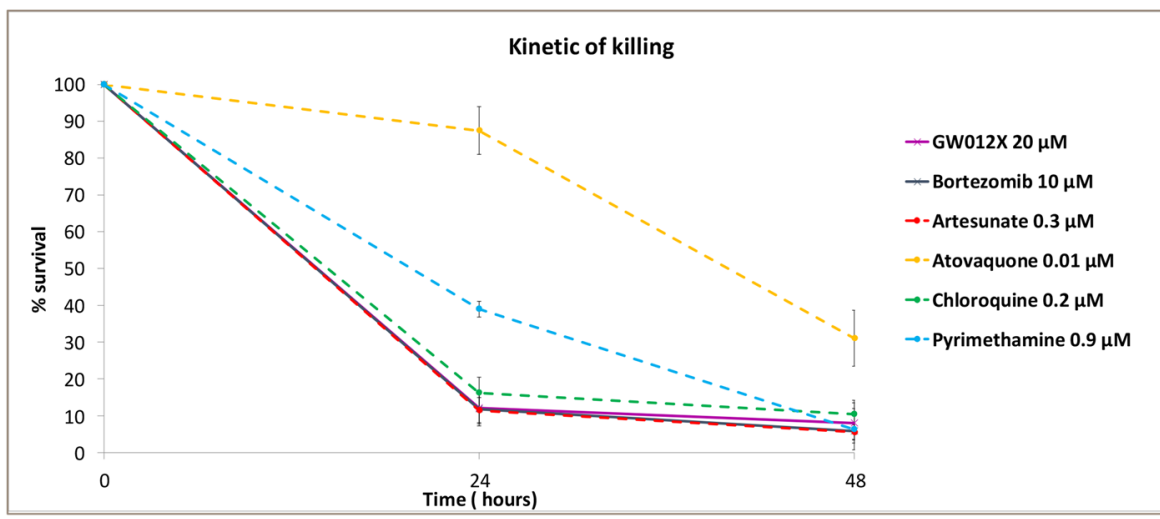

B
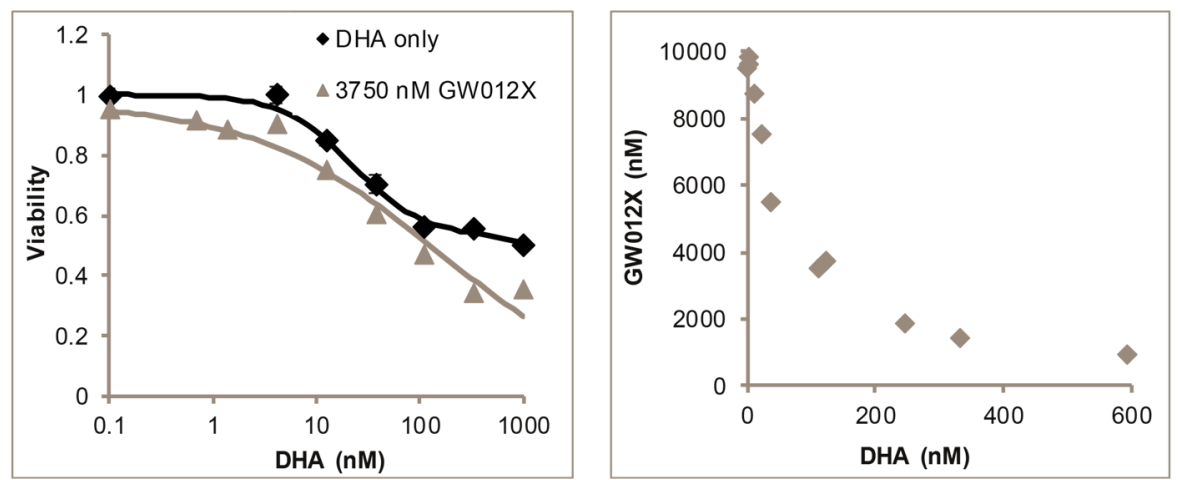

Figure 7. GW012X is fast acting and synergises artemisinin activity against an artemisinin resistant parasite line. (A) Kinetics of killing of the indicated compounds at the indicated concentrations, using the P. falciparum 3D7A strain. Unlabeled erythrocytes were treated for 24 or $48 \mathrm{~h}$. Labeled erythrocytes were added after treatment and incubated for $48 \mathrm{~h}$. Hoechst 33342 was added, and new invasions (double stained erythrocytes) were measured by cytometry. Artesunate and chloroquine are controls with a fast killing profile, pyrimethamine has a moderate profile, and atovaquone is a control with a slow killing profile. (B) Synergistic interaction of GW012X and DHA against Kelch13 mutant parasites. Cam3.II parasites (early ring stage) were exposed to combinations of DHA and GW012X for $3 \mathrm{~h}$. The left panel shows a shift of the DHA inhibition profile in the presence of a sublethal concentration of GW012X (gray curve). The right panel shows an isobologram for the GW012X and DHA pair. Each data point represents the $50 \%$ survival level $\left(\mathrm{IC} 50_{3 \mathrm{~h}}\right.$ ) resulting from a combination of DHA (concentration indicated at $x$-axis) and GW012X (concentration indicated at $y$ axis). Error bars, where present, correspond to the range of technical duplicates. Two independent repeats are presented in SI Figure S6.

(Greiner) with compounds and incubated for $1 \mathrm{~h}$. Then, $4 \mu \mathrm{L}$ of peptide solution dissolved in the same assay buffer was added to the plates. The final concentrations of peptides were $50 \mu \mathrm{M}$ SucLLVY-AMC (500 $\mu \mathrm{M}$ in the assay at 10 times the $\mathrm{Km}$ ), $5 \mu \mathrm{M}$ Suc-LLVY-Rho110, $10 \mu \mathrm{M}$ Ac-RLR-Rho110 (trypsin-like), and $20 \mu \mathrm{M}$ Ac-GPLD-Rho110 (caspase-like). Fluorescence signals were quantitated using a Envision plate reader at $\lambda_{\text {ex } / \mathrm{em}}=380 /$ $460 \mathrm{~nm}$ or $\lambda_{\text {ex } / \mathrm{em}}=485 / 530$ for AMC and Rho110, respectively.

Data analysis and selection criteria. Data were normalized to percentage of inhibition using the following equation $^{1}$

$$
\text { \%Inhibition }(x)=100-100 * \frac{R x-R_{C t r l 1}}{R_{C t r l 1} R_{C t r l 2}}
$$

$R_{x}$ is the assay response measured for compound $\mathrm{X}$, while $R_{\mathrm{Ctrl} 1}$ and $R_{\mathrm{Ctr} 22}$ are calculated as the average of control 1 (columns with $1 \% \mathrm{DMSO}$ ) and control 2 (columns with proteasome inhibitor), respectively, in the same plate of compound $\mathrm{X} . \mathrm{Z}^{\prime}{ }^{2}$, signal to background ratio (S/B), and robust standard deviation (SD) were calculated using Activity Base XE (IDBS) templates.

$$
Z^{\prime}=1-3 *\left[\frac{S D R_{C t r l 1}+S D R_{C t r l 2}}{R_{C t r l 1} R_{C t r l 2}}\right]
$$

Robust cut-offs at robust mean $+3 * \mathrm{SD}$ of Control 1 (estimated through an algorithm; ${ }^{33}$ ) were used to mark the hits in the single concentration assays. For dose response assays, compounds considered were active if they exhibited a percentage inhibition higher than $40 \%$ in enzyme assays and $50 \%$ in whole cell assays in the wells with the highest concentration of compound. pIC50 values $\left(\mathrm{pIC50}=-\log _{10}(\mathrm{IC} 50(\mathrm{M}))\right.$ were obtained using the Activity Base XE nonlinear regression bundle. Data visualization and further analysis were performed using TIBCO Spotfire 3.2 software and XLfit Microsoft Excel bundle. Compounds with pIC50 values lower than $4(>100 \mu \mathrm{M})$ or $4.3(>50 \mu \mathrm{M})$ were considered inactive in the enzyme and whole cell assays, respectively. GSK proprietary compound screening databases were queried for historical data of the hits obtained.

The selection of the 4786 compounds for dose response was performed calculating a score for every hit based on the following formula, ${ }^{3}$ with $\mathrm{X}$ being their corresponding value

Range of $B$ is $[0,1]$

$$
B\left(x, x_{\text {ideal }}, x_{\max }\right)=\left\{\begin{array}{l}
1 \text { if } x \leq x_{\text {ideal }} \\
1.0-\frac{x-x_{\text {ideal }}}{x_{\max }-x_{\text {ideal }}} \text { if } x_{\text {ideal }} \leq x \leq x_{\max } \\
0 \text { if }>x_{\max }
\end{array}\right\}
$$

$$
\begin{array}{ccc}
\text { Parameter } & \text { Min/Max } & \text { Ideal } \\
\text { Potency (\% inhibition at } \mathbf{1 0} \boldsymbol{\mu M}) & 40 \% & \geq 80 \% \\
\text { PFI } & 9.0 & 6.0
\end{array}
$$


A value of 0.5 (present) or 1 (not present) was added to the value obtained if they had structural alerts, cytotoxicity, or a high IFI. IFI is calculated as the number of assays in which the compound has a percentage of inhibition higher than $50 \%$, based on more than 20 assays. Ideally, IFI should be lower than 5 . Compounds were ranked, with less than 5 molecules included per cluster.

Whole Cell Parasite Growth Inhibition Assay $\left({ }^{3} \mathrm{H}-\right.$ Hypoxanthine Incorporation). The $P$. falciparum 3D7A strain was obtained from the Malaria Research and Reference Reagent Resource Center (MR4). A bortezomib-resistant $P$. falciparum (3D7-B1a) line was selected by exposing cultures to increasing drug pressure for 30 weeks, prior to cloning by limiting dilution. ${ }^{9}$ The 3D7A-B1a strain harbors $\beta 5$ subunit Met105Ile and Leu113Phe mutations. ${ }^{9}$ Parasites were cultured as described previously. ${ }^{31}$ Assay was performed using the standard ${ }^{3} \mathrm{H}$-hypoxanthine incorporation method but reading the signal with Scintillation Proximity Assay (SPA) beads (PerkinElmer). Assays were performed in 384 white well plates, as described previously. ${ }^{34}$ Artesunate at $2 \mu \mathrm{M}$ was used as control 2 (100\% inhibition).

Parasite Viability Assay (Flow Cytometry). Drug treatment of parasites was initiated at $0.2 \%$ hematocrit and $1-2 \%$ parasitaemia, in the cycle following synchronization. Drug effect (viability) was assessed when parasites reached the trophozoite stage of the second cycle. For standard $72 \mathrm{~h}$ assays, sorbitoltreated ring stage parasites were continuously exposed to the drugs for $72 \mathrm{~h}$. For $3 \mathrm{~h}$ ring stage and drug interaction (isobologram) assays, tightly synchronized early ring stage parasites ( $0-6 \mathrm{~h}$ after invasion) were subjected to $3 \mathrm{~h}$ drug pulse (as a single drug, or as a two-drug combination) and then returned to culture until the viability was measured. Cells were stained with $2 \mu \mathrm{M}$ SYTO-61 and parasitaemia quantitated by flow cytometry. ${ }^{35,36}$ Data were analyzed using FCS Express software. Viability represents the parasitaemia normalized to untreated and "non-viable" controls, where "non-viable" controls refer to samples treated with $2 \mu \mathrm{M}$ DHA for $48-72$ h. Isobologram analysis was performed as described previously. $^{37}$

Dual Male/Female Gamete Activation Assay. Gametocyte Cultures Were Produced as Previously Described. ${ }^{27}$ Gamete activation was triggered by reducing the temperature and adding an ookinete medium containing xanthurenic acid, supplemented with the antibody anti-Pfs $25-\mathrm{Cy} 3$ at a final concentration of $1: 2000$. This culture was incubated at $26^{\circ} \mathrm{C}$ for $24 \mathrm{~h}$ to increase the fluorescence signal marking the female gametes. In the assay of activation of male gametes, the light change produced by flagella movements and the movement that causes in the surrounding cells was monitored. A 10-frame video was taken and subsequently analyzed to determine changes in cell position based on pixels change. In the case of the activation of female gametes it was based on the detection of fluorescence from bound Cy3-anti-Pfs 25 antibody (as the primary parameter), followed by selection of events according to their size, roundness, and the intensity of the fluorescence

HepG2 Cytotoxicity Assay. A luminescence assay previously described using the CellTiter-Glo Luminescent Cell Viability Assay kit (Promega) was used to assess the acute cytotoxic effect of compounds in human liver-derived HepG2 cells (ATCC). ${ }^{38}$ The luminescence signal was quantified using an Envision Multilabel Reader (PerkinElmer).

Physicochemical Properties. Artificial membrane permeability and chromatographic $\log \mathrm{D}$ at $\mathrm{pH} 7.4$ were measured using published protocols. ${ }^{39,40}$ Kinetic solubility was measured using the HPLC-CAD technique. The kinetic aqueous solubility at $\mathrm{pH} 7.4$ was determined by measuring the concentration of solute in solution after precipitation from DMSO stock solution. The DMSO stock solution was diluted 20-fold with PBS pH7.4, and the solubility of the compound was measured after equilibration for $1 \mathrm{~h}$ at room temperature. In this procedure, quantification was done using a Charged Aerosol Detector (CAD). The actual DMSO concentration of the stock solution was also determined using this technique. Calibration parameters generated for $\mathrm{CAD}$ response of two calibrants (Primidone and Ketoconazole) were used to calculate the solubility of solutes taking into account the density of the compound and ion-pairing effects. ${ }^{41}$ The PFI parameter is the ChromLogD plus the number of aromatic rings. ${ }^{26}$

Rate of Killing. The kinetics of killing of the P. falciparum 3D7A strain were determined following the protocol previously described. ${ }^{30}$ Briefly, $100 \mu \mathrm{L}$ of unlabeled erythrocytes infected with P. falciparum at $0.5 \%$ parasitaemia (hematocrit $2 \%$ ) were added to 96-well plates with compound GW012X, at around 10 times its IC50 value. Culture was treated for 24 or $48 \mathrm{~h}$ before compound was washed out. The same procedure was followed with standard compounds, bortezomib (10 $\mu \mathrm{M}$; fast), chloroquine $(0.2 \mu \mathrm{M}$; fast $)$, pyrimethamine $(0.9 \mu \mathrm{M}$; moderate), atovaquone $(0.01 \mu \mathrm{M}$; slow), and artesunate ( $0.3 \mu \mathrm{M}$; fast) for comparison. The culture was diluted 1:3 with erythrocytes prelabeled with $10 \mu \mathrm{M}$ carboxyfluorescein diacetate succinimidyl ester (CFDA-SE; Life Technologies) at $2 \%$ hematocrit in RPMI 1640 medium. After $48 \mathrm{~h}$ of incubation, the medium was removed, and the parasites were labeled with $100 \mu \mathrm{L}$ of Hoechst 33342 (Sigma) at $1.2 \mu \mathrm{g} / \mathrm{mL}$ in PBS. The ability of treated parasites to establish new infections in the labeled erythrocytes was detected by the quantification of double-stained erythrocytes using two-color flow cytometry (Attune NxT Flow Cytometer, ThermoFisher), with excitation at 405 and $488 \mathrm{~nm}$ and emission at 440 and $530 \mathrm{~nm}$, for Hoechst and CFDA-SE, respectively.

GFP-DD Reporter Assay and Ubiquitylation Level Assay. Transfectants expressing GFP fused to a destabilization domain (GFP-DD) were generated as previously described. ${ }^{28}$ Trophozoite stage GFP-DD or 3D7A parasites at 5\% hematocrit and $4-5 \%$ parasitaemia were exposed to the drugs at the indicated concentrations for 3 or $1.5 \mathrm{~h}$ at $37^{\circ} \mathrm{C}$. Following drug treatment, cell pellets were washed with PBS supplemented with protease inhibitor cocktail, and parasites were extracted using $0.01-0.05 \% \mathrm{w} / \mathrm{v}$ saponin. Parasite pellets were washed 3 times with PBS before being resuspended in SDS-PAGE sample loading buffer and then boiled at $95{ }^{\circ} \mathrm{C}$. Samples were resolved by SDS-PAGE and transferred to nitrocellulose membranes. For the GFP-DD assay, blots were blocked in 4\% skim milk and incubated with the primary antibody anti-GFP antibody (1:1000, Roche) and then with secondary antibody goat antimouse IgG peroxidase (1:10000). For the ubiquitylation assay, samples were prepared as before, but vortexed instead, and maintained at $95{ }^{\circ} \mathrm{C}$ before being loaded onto SDS-page gels. The blots were boiled for 20 min directly after transfer and were then blocked. The blot was incubated with rabbit antiubiquitin antibody (Dako 1:1500 or Cell Signaling Technology) followed by incubation with goat antirabbit IgG peroxidase (Sigma-Aldrich 1:40000). Pf Bip was used as loading control. Polyclonal mouse anti-PfBip antibody (1:1000) was generated using recombinant $P f B i P$ at the WEHI Antibody 
Services. $^{28}$ Blots were visualized using Clarity Western ECL substrate.

\section{CONCLUSION}

A screening campaign of almost 550000 compounds has been run on the the basis of the establishment of an improved Proteasome-GLO chymotrypsin-like activity assay and a new Rho110 florescence assay format. To our knowledge, this is the highest number of compounds ever tested against the $P$. falciparum proteasome. This is a huge undertaking but is critical to the process of identifying new leads for malaria treatment. As a result, four nonpeptidomimetic chemical families with some selectivity for P. falciparum proteasome were identified and fully characterized. Target engagement studies were performed, validating our approach.

After testing a large number of compounds, representing a very wide chemical diversity, we did not find potent and selective compounds. We were able to identify potent compounds but all of them also inhibited the human counterpart. We conclude that the very high homology between the parasite and human proteasomes makes it difficult to find small and selective molecules, unlike that in the case for the Leishmania donovani proteasome. ${ }^{21}$ The Leishmania-specific compounds bind to a binding pocket that does not exist in $P$. falciparum. We have tested hundreds of compounds selective for the kinetoplastid proteasome, but these were inactive against $P$. falciparum (data not shown).

Although the potency and specificity need to be further increased, the four clusters identified have advantages over other published parasite proteasome inhibitors of being small, nonpeptide-mimetic molecules with good drug-like properties. They, therefore, represent advanced starting points for the development of novel, antimalarial drugs. In particular, compound GW012X shows a fast-acting parasitological profile and strong synergy with DHA against an artemisinin-resistant line, which are desired properties for new therapeutics in the context of emerging resistance to available treatments.

\section{ASSOCIATED CONTENT}

\section{SI Supporting Information}

The Supporting Information is available free of charge at https://pubs.acs.org/doi/10.1021/acsinfecdis.1c00110.

Structures of the three peptides used in the Rho110 assay and cross-titration of human or P. falciparum proteasomes with the three proteasome substrates labeled with Rho110; correlation of the percent inhibition obtained for each replicate in the chymotrypsin-like Rho110 assay; dose response of the best compounds selected per cluster; dose response of the best compounds selected per cluster in the whole cell parasite viability assay; independent repeats of the experiments depicted in Figure 6; independent repeats of the experiments depicted in Figure $7 \mathrm{~B}$; selective hits for the P. falciparum proteasome (PDF)

\section{AUTHOR INFORMATION}

\section{Corresponding Author}

Lydia Mata-Cantero - Global Health Discovery Incubator Unit, Global Health R\&D. GlaxoSmithKline, Tres Cantos 28760, Madrid, Spain; 이이.org/0000-0002-1924-3614; Email: lydia.c.mata@gsk

\section{Authors}

Stanley C. Xie - Department of Biochemistry and Pharmacology, Bio21 Molecular Science and Biotechnology Institute, University of Melbourne, Melbourne, Victoria 3010, Australia; (1) orcid.org/0000-0001-7003-4677

Mercedes García - MST-MedDesign-MedChem R\&D. GlaxoSmithKline, Tres Cantos 28760, Madrid, Spain

Joanne Coyle - Department of Biochemistry and Pharmacology, Bio21 Molecular Science and Biotechnology Institute, University of Melbourne, Melbourne, Victoria 3010, Australia

Raquel Fernandez - MST-MedDesign-MedChem R\&D. GlaxoSmithKline, Tres Cantos 28760, Madrid, Spain

Alvaro Cortes Cabrera - MST-MedDesign-MedChem R\&D. GlaxoSmithKline, Tres Cantos 28760, Madrid, Spain; (1) orcid.org/0000-0003-4635-6267

David L. Gillett - Department of Biochemistry and Pharmacology, Bio21 Molecular Science and Biotechnology Institute, University of Melbourne, Melbourne, Victoria 3010, Australia

Benigno Crespo - Global Health Discovery Incubator Unit, Global Health R\&D. GlaxoSmithKline, Tres Cantos 28760, Madrid, Spain

Francisco-Javier Gamo - Global Health Discovery Incubator Unit, Global Health R\&D. GlaxoSmithKline, Tres Cantos 28760, Madrid, Spain; (1) orcid.org/0000-0002-1854-2882

Esther Fernández - Global Health Discovery Incubator Unit, Global Health R\&D. GlaxoSmithKline, Tres Cantos 28760, Madrid, Spain; 이이.org/0000-0002-0507-8507

Leann Tilley - Department of Biochemistry and Pharmacology, Bio21 Molecular Science and Biotechnology Institute, University of Melbourne, Melbourne, Victoria 3010, Australia; (orcid.org/0000-0001-9910-0199

Maria G. Gomez-Lorenzo - Global Health Discovery Incubator Unit, Global Health R\&D. GlaxoSmithKline, Tres Cantos 28760, Madrid, Spain; (1) orcid.org/0000-00032065-1145

Complete contact information is available at:

https://pubs.acs.org/10.1021/acsinfecdis.1c00110

\section{Notes}

The authors declare no competing financial interest.

\section{ACKNOWLEDGMENTS}

The project has been cofunded by the Tres Cantos Open Lab Foundation (TCOLF), GSK, and the Australian National Health and Medical Research Council. Human erythrocytes were supplied by the Centro de transfusión sanguínea de la CAM (Madrid, Spain), Centro de Hemoterapia y Hemodonación de Castilla y León (Valladolid, Spain) and the Red Cross Blood Service, Australia. Human biological samples were sourced ethically, and their research use complied with the terms of the informed consent under an IRB/EC approved protocol. The following reagent was obtained through $\mathrm{BEI}$ Resources, NIAID, NIH: P. falciparum, Strain 3D7A, MRA-151, contributed by David Walliker. NF54 used in the dual gamete formation assay was obtained through BEI Resources, NIAID, NIH: P. falciparum, Strain NF54 (Patient Line E), MRA-1000, contributed by Megan G. Dowler. We thank Albert Isidro Llobet from NCE-MD-Chemical Biology GSK for providing us the Rho110 peptides. We thank Dr. Paul Gilson, Prof. Brendan Crabb, and Dr. Mauro F. Azevedo, Burnet Institute, for the DD- 
GFP parasite line. We also thank Maria Jesús Almela for testing compounds in the dual gamete activation assay.

\section{ABBREVIATIONS}

ACT, artemisinin combination therapies; UPS, Ubiquitin Proteasome System; HTS, high throughput screening; Rho110, D-Pro-Rhodamine110; AMC, 7-amino-4-methylcoumarin; AML, aminoluciferin; hPA28 $\alpha$, human PA28 $\alpha$ activator; S/B, signal to background; SD, standard deviation; TCAMs, Tres Cantos Antimalarial Set; PFI, Property Forecast Index; IFI, Inhibition Frequency Index; SAR, structure-activity relationship; DD, destabilization domain; WR, WR99210; DHA, dihydroartemisinin

\section{REFERENCES}

(1) WHO. 2019. World Malaria Report.

(2) Gamo, F. J. (2014) Antimalarial drug resistance: new treatments options for Plasmodium. Drug Discovery Today: Technol. 11, 81-88.

(3) Bedford, L., Paine, S., Sheppard, P. W., Mayer, R. J., and Roelofs, J. (2010) Assembly, structure, and function of the 26S proteasome. Trends Cell Biol. 20, 391-401.

(4) Mata-Cantero, L, Lobato-Gil, S, Aillet, F, and Rodriguez, M. S. The ubiquitin proteasome system (UPS) as a cancer drug target: emerging mechanisms and therapeutics, p 225-264. In Wondrak, S. L. (ed), The ubiquitin proteasome system (UPS) as a cancer drug target: emerging mechanisms and therapeutics;Springer Science Business Media: 2015

(5) Mata-Cantero, L AM, Aillet, F., Xolalpa, W., LaFuente, M. J., Elortza, F., Carvalho, A. S., Martin-Plaza, J., Matthiesen, R., and Rodriguez, M. S. (2016) New insights into host-parasite ubiquitin proteome dynamics in P. falciparum infected red blood cells using a TUBEs-MS approach. J. Proteomics 139, 45-59.

(6) Li, H., Ponder, E. L., Verdoes, M., Asbjornsdottir, K. H., Deu, E., Edgington, L. E., Lee, J. T., Kirk, C. J., Demo, S. D., Williamson, K. C., and Bogyo, M. (2012) Validation of the proteasome as a therapeutic target in Plasmodium using an epoxyketone inhibitor with parasitespecific toxicity. Chem. Biol. 19, 1535-1545.

(7) Dogovski, C., Xie, S. C., Burgio, G., Bridgford, J., Mok, S., McCaw, J. M., Chotivanich, K., Kenny, S., Gnadig, N., Straimer, J., Bozdech, Z., Fidock, D. A., Simpson, J. A., Dondorp, A. M., Foote, S., Klonis, N., and Tilley, L. (2015) Targeting the cell stress response of Plasmodium falciparum to overcome artemisinin resistance. PLoS Biol. 13, No. e1002132.

(8) Li, H., O’Donoghue, A. J., van der Linden, W. A., Xie, S. C., Yoo, E., Foe, I. T., Tilley, L., Craik, C. S., da Fonseca, P. C. A., and Bogyo, M. (2016) Structure and function based design of Plasmodium-selective proteasome inhibitors. Nature 530, 233-236.

(9) Xie, S. C., Gillett, D. L., Spillman, N. J., Tsu, C., Luth, M. R., Ottilie, S., Duffy, S., Gould, A. E., Hales, P., Seager, B. A., Charron, C. L., Bruzzese, F., Yang, X., Zhao, X., Huang, S. C., Hutton, C. A., Burrows, J. N., Winzeler, E. A., Avery, V. M., Dick, L. R., and Tilley, L. (2018) Target Validation and Identification of Novel Boronate Inhibitors of the Plasmodium falciparum Proteasome. J. Med. Chem. 61, 1005310066 .

(10) Zhan, W., Visone, J., Ouellette, T., Harris, J. C., Wang, R., Zhang, H., Singh, P. K., Ginn, J., Sukenick, G. D., Wong, T. T., Okoro, J. I., Scales, R. M., Tumwebaze, P. T., Rosenthal, P. J., Kafsack, B. F. C., Cooper, R., Meinke, P. T., Kirkman, L. A., and Lin, G. (2019) Improvement of asparagine ethylenediamines as anti-malarial Plasmodium-selective proteasome inhibitors. J. Med. Chem. 62, 6137.

(11) Xie, S. C., Dick, L. R., Gould, A., Brand, S., and Tilley, L. (2019) The proteasome as a target for protozoan parasites. Expert Opin. Ther. Targets 23, 903-914.

(12) Pereira, P. H. S., Curra, C., and Garcia, C. R. S. (2018) Ubiquitin Proteasome System as a Potential Drug Target for Malaria. Curr. Top. Med. Chem. 18, 315-320.
(13) Mata-Cantero, L., Chaparro, M. J., Colmenarejo, G., Cid, C., Cortes Cabrera, A., Rodriguez, M. S., Martin, J., Gamo, F. J., and Gomez-Lorenzo, M. G. (2019) Identification of Small Molecules Disrupting the Ubiquitin Proteasome System in Malaria. ACS Infect. Dis. 5, 2105-2117.

(14) Kirkman, L. A., Zhan, W., Visone, J., Dziedziech, A., Singh, P. K., Fan, H., Tong, X., Bruzual, I., Hara, R., Kawasaki, M., Imaeda, T., Okamoto, R., Sato, K., Michino, M., Alvaro, E. F., Guiang, L. F., Sanz, L., Mota, D. J., Govindasamy, K., Wang, R., Ling, Y., Tumwebaze, P. K., Sukenick, G., Shi, L., Vendome, J., Bhanot, P., Rosenthal, P. J., Aso, K., Foley, M. A., Cooper, R. A., Kafsack, B., Doggett, J. S., Nathan, C. F., and Lin, G. (2018) Antimalarial proteasome inhibitor reveals collateral sensitivity from intersubunit interactions and fitness cost of resistance. Proc. Natl. Acad. Sci. U. S. A. 115, E6863-E6870.

(15) Groll, M., Berkers, C. R., Ploegh, H. L., and Ovaa, H. (2006) Crystal structure of the boronic acid-based proteasome inhibitor bortezomib in complex with the yeast 20 S proteasome. Structure 14 , 451-456.

(16) Schrader, J., Henneberg, F., Mata, R. A., Tittmann, K., Schneider, T. R., Stark, H., Bourenkov, G., and Chari, A. (2016) The inhibition mechanism of human $20 \mathrm{~S}$ proteasomes enables next-generation inhibitor design. Science 353, 594-598.

(17) Li, H., van der Linden, W. A., Verdoes, M., Florea, B. I., McAllister, F. E., Govindaswamy, K., Elias, J. E., Bhanot, P., Overkleeft, H. S., and Bogyo, M. (2014) Assessing subunit dependency of the Plasmodium proteasome using small molecule inhibitors and active site probes. ACS Chem. Biol. 9, 1869-1876.

(18) Yoo, E., Stokes, B. H., de Jong, H., Vanaerschot, M., Kumar, T., Lawrence, N., Njoroge, M., Garcia, A., Van der Westhuyzen, R., Momper, J. D., Ng, C. L., Fidock, D. A., and Bogyo, M. (2018) Defining the determinants of specificity of Plasmodium proteasome inhibitors. J. Am. Chem. Soc. 140, 11424-11437.

(19) Britton, M., Lucas, M. M., Downey, S. L., Screen, M., Pletnev, A. A., Verdoes, M., Tokhunts, R. A., Amir, O., Goddard, A. L., Pelphrey, P. M., Wright, D. L., Overkleeft, H. S., and Kisselev, A. F. (2009) Selective inhibitor of proteasome's caspase-like sites sensitizes cells to specific inhibition of chymotrypsin-like sites. Chem. Biol. 16, 1278-1289.

(20) Kisselev, A. F., and Goldberg, A. L. (2005) Monitoring activity and inhibition of $26 \mathrm{~S}$ proteasomes with fluorogenic peptide substrates. Methods Enzymol. 398, 364-378.

(21) Wyllie, S., Brand, S., Thomas, M., De Rycker, M., Chung, C.-w., Pena, I., Bingham, R. P., Bueren-Calabuig, J. A., Cantizani, J., Cebrian, D., Craggs, P. D., Ferguson, L., Goswami, P., Hobrath, J., Howe, J., Jeacock, L., Ko, E.-J., Korczynska, J., MacLean, L., Manthri, S., Martinez, M. S., Mata-Cantero, L., Moniz, S., Nuhs, A., Osuna-Cabello, M., Pinto, E., Riley, J., Robinson, S., Rowland, P., Simeons, F. R. C., Shishikura, Y., Spinks, D., Stojanovski, L., Thomas, J., Thompson, S., Viayna Gaza, E., Wall, R. J., Zuccotto, F., Horn, D., Ferguson, M. A. J., Fairlamb, A. H., Fiandor, J. M., Martin, J., Gray, D. W., Miles, T. J., Gilbert, I. H., Read, K. D., Marco, M., and Wyatt, P. G. (2019) Preclinical candidate for the treatment of visceral leishmaniasis that acts through proteasome inhibition. Proc. Natl. Acad. Sci. U. S. A. 116, 93189323.

(22) Auld, D. S. I. J.. 2016. Interferences with Luciferase Reporter Enzymes. Eli Lilly \& Company and the National Center for Advancing Translational Sciences, Bethesda (MD); 2004, Assay Guidance Manual.

(23) Simeonov, A, and Davis, M. I.. 2004. Interference with Fluorescence and Absorbance. In Sittampalam, G. S., Grossman, A, Brimacombe, K, Arkin, M, Auld, D, Austin, C. P., Baell, J, Bejcek, B, Caaveiro, J. M. M., Chung, T. D. Y., Coussens, N. P., Dahlin, J. L., Devanaryan, V, Foley, T. L., Glicksman, M, Hall, M. D., Haas, J. V., Hoare, S. R. J., Inglese, J, Iversen, P. W., Kahl, S. D., Kales, S. C., Kirshner, S, Lal-Nag, M, Li, Z, McGee, J, McManus, O, Riss, T, Saradjian, P, Trask, O. J., Jr., Weidner, J. R., Wildey, M. J., Xia, M, and Xu, X (ed), Assay Guidance Manual, Bethesda (MD).

(24) Gamo, F.-J., Sanz, L. M., Vidal, J., de Cozar, C., Alvarez, E., Lavandera, J.-L., Vanderwall, D. E., Green, D. V. S., Kumar, V., Hasan, S., Brown, J. R., Peishoff, C. E., Cardon, L. R., and Garcia-Bustos, J. F. 
(2010) Thousands of chemical starting points for antimalarial lead identification. Nature 465, 305-310.

(25) Leach, A, and Guillet, V. 2007. Selecting Diverse Sets of Compounds: Hierarchical Clustering. Springer: Dordrecht, Netherlands, An Introduction to Chemoinformatics.

(26) Young, R. J., Green, D. V., Luscombe, C. N., and Hill, A. P. (2011) Getting physical in drug discovery II: the impact of chromatographic hydrophobicity measurements and aromaticity. Drug Discovery Today 16, 822-830.

(27) Ruecker, A., Mathias, D. K., Straschil, U., Churcher, T. S., Dinglasan, R. R., Leroy, D., Sinden, R. E., and Delves, M. J. (2014) A male and female gametocyte functional viability assay to identify biologically relevant malaria transmission-blocking drugs. Antimicrob. Agents Chemother. 58, 7292-7302.

(28) Bridgford, J. L., Xie, S. C., Cobbold, S. A., Pasaje, C. F. A., Herrmann, S., Yang, T., Gillett, D. L., Dick, L. R., Ralph, S. A., Dogovski, C., Spillman, N. J., and Tilley, L. (2018) Artemisinin kills malaria parasites by damaging proteins and inhibiting the proteasome. Nat. Commun. 9, 3801.

(29) Mata-Cantero, L., Cid, C., Gomez-Lorenzo, M. G., Xolalpa, W., Aillet, F., Martin, J. J., and Rodriguez, M. S. (2015) Development of two novel high-throughput assays to quantify ubiquitylated proteins in cell lysates: application to screening of new anti-malarials. Malar. J. 14, 200.

(30) Linares, M., Viera, S., Crespo, B., Franco, V., Gomez-Lorenzo, M. G., Jimenez-Diaz, M. B., Angulo-Barturen, I., Sanz, L. M., and Gamo, F. J. (2015) Identifying rapidly parasiticidal anti-malarial drugs using a simple and reliable in vitro parasite viability fast assay. Malar. J. 14, 441.

(31) Tallarida, R. J. (2006) An overview of drug combination analysis with isobolograms. J. Pharmacol. Exp. Ther. 319, 1-7.

(32) Masters, E. I., Pratt, G., Forster, A., and Hill, C. P. (2005) Purification and analysis of recombinant $11 \mathrm{~S}$ activators of the $20 \mathrm{~S}$ proteasome: Trypanosoma brucei PA26 and human PA28 alpha, PA28 beta, and PA28 gamma. Methods Enzymol. 398, 306-321.

(33) Analytical Methods Committee. Analyst1989. Robust Statistics-How Not to Reject Outliers, p 1693-1697. In Analyst (ed), vol 114.

(34) de Cozar, C., Caballero, I., Colmenarejo, G., Sanz, L. M., AlvarezRuiz, E., Gamo, F.-J., and Cid, C. (2016) Development of a Novel HighDensity $[3 \mathrm{H}]$ Hypoxanthine Scintillation Proximity Assay To Assess Plasmodium falciparum Growth. Antimicrob. Agents Chemother. 60, $5949-5956$.

(35) Fu, Y., Tilley, L., Kenny, S., and Klonis, N. (2010) Dual labeling with a far red probe permits analysis of growth and oxidative stress in $P$. falciparum-infected erythrocytes. Cytometry A 77, 253-263.

(36) Xie, S. C., Dogovski, C., Kenny, S., Tilley, L., and Klonis, N. (2014) Optimal assay design for determining the in vitro sensitivity of ring stage Plasmodium falciparum to artemisinins. Int. J. Parasitol. 44, 893-899.

(37) del Pilar Crespo, M., Avery, T. D., Hanssen, E., Fox, E., Robinson, T. V., Valente, P., Taylor, D. K., and Tilley, L. (2008) Artemisinin and a series of novel endoperoxide antimalarials exert early effects on digestive vacuole morphology. Antimicrob. Agents Chemother. 52, 98109.

(38) Crouch, S.P.M., Kozlowski, R., Slater, K.J., and Fletcher, J. (1993) the use of ATP bioluminescence as a measure of cellproliferation and cytotoxicity. J. Immunol. Methods 160, 81-88.

(39) Ballell, L., Bates, R. H., Young, R. J., Alvarez-Gomez, D., AlvarezRuiz, E., Barroso, V., Blanco, D., Crespo, B., Escribano, J., Gonzalez, R., Lozano, S., Huss, S., Santos-Villarejo, A., Martin-Plaza, J. J., Mendoza, A., Rebollo-Lopez, M. J., Remuinan-Blanco, M., Lavandera, J. L., PerezHerran, E., Gamo-Benito, F. J., Garcia-Bustos, J. F., Barros, D., Castro, J. P., and Cammack, N. (2013) Fueling open-source drug discovery: 177 small-molecule leads against tuberculosis. ChemMedChem 8, 313-321.

(40) Valko, K., Bevan, C., and Reynolds, D. (1997) Chromatographic Hydrophobicity Index by Fast-Gradient RP-HPLC: A High-Throughput Alternative to $\log$ P/log D. Anal. Chem. 69, 2022-2029.

(41) Robinson, M. W., Hill, A. P., Readshaw, S. A., Hollerton, J. C., Upton, R. J., Lynn, S. M., Besley, S. C., and Boughtflower, B. J. (2017) Use of Calculated Physicochemical Properties to Enhance Quantitative
Response When Using Charged Aerosol Detection. Anal. Chem. 89, 1772-1777. 


\section{University Library}

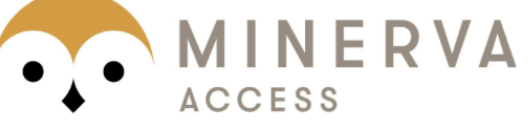

A gateway to Melbourne's research publications

Minerva Access is the Institutional Repository of The University of Melbourne

Author/s:

Mata-Cantero, L;Xie, SC;Garcia, M;Coyle, J;Fernandez, R;Cortes Cabrera, A;Gillett, DL;Crespo, B;Gamo, F-J;Fernandez, E;Tilley, L;Gomez-Lorenzo, MG

Title:

High Throughput Screening to Identify Selective and Nonpeptidomimetic Proteasome Inhibitors As Antimalarials

Date:

2021-05-28

Citation:

Mata-Cantero, L., Xie, S. C., Garcia, M., Coyle, J., Fernandez, R., Cortes Cabrera, A., Gillett, D. L., Crespo, B., Gamo, F. -J., Fernandez, E., Tilley, L. \& Gomez-Lorenzo, M. G. (2021). High Throughput Screening to Identify Selective and Nonpeptidomimetic Proteasome Inhibitors As Antimalarials. ACS INFECTIOUS DISEASES, 7 (6), pp. 1818-1832. https:// doi.org/10.1021/acsinfecdis.1c00110.

Persistent Link:

http://hdl.handle.net/11343/280692

License:

CC BY-NC-ND 